\title{
Measurements of diurnal variations and eddy covariance (EC) fluxes of glyoxal in the tropical marine boundary layer: description of the Fast LED-CE-DOAS instrument
}

\author{
S. Coburn ${ }^{1,2}$, I. Ortega ${ }^{1,2}$, R. Thalman ${ }^{1,2, *}$, B. Blomquist ${ }^{3}$, C. W. Fairall ${ }^{4}$, and R. Volkamer ${ }^{1,2}$ \\ ${ }^{1}$ Department of Chemistry and Biochemistry, University of Colorado, Boulder, CO, USA \\ ${ }^{2}$ CIRES - Cooperative Institute for Research in Environmental Sciences, Boulder, CO, USA \\ ${ }^{3}$ Department of Oceanography, University of Hawaii, Honolulu, HI, USA \\ ${ }^{4}$ Earth System Research Laboratory, NOAA, Boulder, CO, USA \\ *now at: Brookhaven National Laboratory, Upton, NY, USA
}

Correspondence to: R. Volkamer (rainer.volkamer@colorado.edu)

Received: 14 May 2014 - Published in Atmos. Meas. Tech. Discuss.: 20 June 2014

Revised: 10 September 2014 - Accepted: 19 September 2014 - Published: 28 October 2014

\begin{abstract}
Here we present first eddy covariance (EC) measurements of fluxes of glyoxal, the smallest $\alpha$-dicarbonyl product of hydrocarbon oxidation, and a precursor for secondary organic aerosol (SOA). The unique physical and chemical properties of glyoxal - i.e., high solubility in water (effective Henry's law constant, $K_{\mathrm{H}}=4.2 \times 10^{5} \mathrm{M} \mathrm{atm}^{-1}$ ) and short atmospheric lifetime ( $\sim 2 \mathrm{~h}$ at solar noon) - make it a unique indicator species for organic carbon oxidation in the marine atmosphere. Previous reports of elevated glyoxal over oceans remain unexplained by atmospheric models. Here we describe a Fast Light-Emitting Diode Cavity-Enhanced Differential Optical Absorption Spectroscopy (Fast LED-CEDOAS) instrument to measure diurnal variations and EC fluxes of glyoxal and inform about its unknown sources. The fast in situ sensor is described, and first results are presented from a cruise deployment over the eastern tropical Pacific Ocean $\left(20^{\circ} \mathrm{N}\right.$ to $10^{\circ} \mathrm{S} ; 133$ to $\left.85^{\circ} \mathrm{W}\right)$ as part of the Tropical Ocean tRoposphere Exchange of Reactive halogens and Oxygenated VOCs (TORERO) field experiment (January to March 2012). The Fast LED-CE-DOAS is a multispectral sensor that selectively and simultaneously measures glyoxal (CHOCHO), nitrogen dioxide $\left(\mathrm{NO}_{2}\right)$, oxygen dimers $\left(\mathrm{O}_{4}\right)$, and water vapor $\left(\mathrm{H}_{2} \mathrm{O}\right)$ with $\sim 2 \mathrm{~Hz}$ time resolution (Nyquist frequency $\sim 1 \mathrm{~Hz}$ ) and a precision of $\sim 40 \mathrm{pptv} \mathrm{Hz}^{-0.5}$ for glyoxal. The instrument is demonstrated to be a "whitenoise" sensor suitable for EC flux measurements. Fluxes of glyoxal are calculated, along with fluxes of $\mathrm{NO}_{2}, \mathrm{H}_{2} \mathrm{O}$, and
\end{abstract}

$\mathrm{O}_{4}$, which are used to aid the interpretation of the glyoxal fluxes. Further, highly sensitive and inherently calibrated glyoxal measurements are obtained from temporal averaging of data (e.g., detection limit smaller than $2.5 \mathrm{pptv}$ in an hour). The campaign average mixing ratio in the Southern Hemisphere ( $\mathrm{SH})$ is found to be $43 \pm 9$ pptv glyoxal, which is higher than the Northern Hemisphere $(\mathrm{NH})$ average of $32 \pm 6 \mathrm{pptv}$ (error reflects variability over multiple days). The diurnal variation of glyoxal in the marine boundary layer (MBL) is measured for the first time, and mixing ratios vary by $\sim 8$ pptv $(\mathrm{NH})$ and $\sim 12$ pptv $(\mathrm{SH})$ over the course of $24 \mathrm{~h}$. Consistently, maxima are observed at sunrise (NH: $35 \pm 5$ pptv; SH: $47 \pm 7 \mathrm{pptv}$ ), and minima at dusk (NH: $27 \pm 5$ pptv; SH: $35 \pm 8$ pptv). In both hemispheres, the daytime flux was directed from the atmosphere into the ocean, indicating that the ocean is a net sink for glyoxal during the day. After sunset the ocean was a source for glyoxal to the atmosphere (positive flux) in the $\mathrm{SH}$; this primary ocean source was operative throughout the night. In the $\mathrm{NH}$, the nighttime flux was positive only shortly after sunset and negative during most of the night. Positive EC fluxes of soluble glyoxal over oceans indicate the presence of an ocean surface organic microlayer (SML) and locate a glyoxal source within the SML. The origin of most atmospheric glyoxal, and possibly other oxygenated hydrocarbons over tropical oceans, remains unexplained and warrants further investigation. 


\section{Introduction}

Eddy covariance (EC) fluxes are a well-established and widely used technique to measure surface-atmosphere gas exchange. The EC flux method provides insight into sources and sinks of atmospheric parameters (physical and chemical state variables) suitable to test our process-level understanding (Baldocchi et al., 2001). EC fluxes are defined as the time average covariance between deviations from the mean of vertical wind velocity and deviations from the mean in the parameter of interest, e.g., here, the mixing ratio of a trace gas:

$F_{\mathrm{c}}=\overline{w^{\prime} c^{\prime}}=\int_{0}^{f_{\mathrm{n}}} C_{\mathrm{wc}}(f) \mathrm{d} f$,

where $F$ is the flux, $w^{\prime}$ is the vertical wind velocity component, $c^{\prime}$ is the mixing ratio of the trace gas component, the prime denotes the instantaneous deviation from the mean, $f_{\mathrm{n}}$ is the Nyquist frequency of the measurements, and $C_{\mathrm{wc}}$ is the cospectrum.

A requirement of the EC flux technique is that measurements of both vertical wind velocities and the trace gas of interest are performed at high sampling frequencies, $f$ (typically a minimum of several $\mathrm{Hz}$ ), sufficient to capture a majority of those frequencies that contribute to the overall flux. Balancing this requirement with preserving sufficient sensitivity in the measurements is one of the major challenges with developing chemical sensors suitable for EC flux applications. For mobile deployments, a portable and robust sensor is needed. Further, additional measurements of platform motion need to be performed, and corrections on the wind velocity data are needed. A description of the system deployed in this study and the method of correction is described by Fairall et al. (1997) and Edson et al. (1998), respectively. A particular challenge arises for EC flux measurements of short-lived species in the marine boundary layer (MBL), for which concentrations often do not exceed tens to hundreds of parts per trillion $\left(1 \mathrm{pptv}=10^{-12}\right.$ volume mixing ratio $($ VMR $)=2.46 \times 10^{7}$ molecules $\mathrm{cm}^{-3}$ at $298 \mathrm{~K}$ temperature and 1013 mbar pressure). As a result of these challenges, ship based EC flux measurements have today only been reported for the seven trace molecules: dimethyl sulfide (DMS) (Huebert et al., 2004; Blomquist et al., 2006, 2010; Marandino et al., 2007, 2008, 2009; Miller et al., 2009; Bell et al., 2013), carbon dioxide $\left(\mathrm{CO}_{2}\right)$ (Fairall et al., 2000; McGillis et al., 2001, 2004; Kondo and Tsukamoto, 2007; Miller et al., 2009, 2010; Taddei et al., 2009; Edson et al., 2011; Norman et al., 2012), ozone $\left(\mathrm{O}_{3}\right)$ (Bariteau et al., 2010; Helmig et al., 2012), carbon monoxide (CO) (Blomquist et al., 2012), acetone (Marandino et al., 2005; Taddei et al., 2009; Yang et al., 2014), acetaldehyde (Yang et al., 2014), and methanol (Yang et al., 2013). Table 1 lists typical concentrations for these molecules in the MBL and compares them with glyoxal in terms of their Henry's law constants $\left(K_{\mathrm{H}}\right.$, at $\left.298 \mathrm{~K}\right)$ and typical atmospheric lifetimes. Notably, glyoxal is the molecule with the shortest atmospheric lifetime, and it is present in the lowest abundance. The short lifetime of glyoxal limits the spatial scale over which it can be transported in the atmosphere to a few tens of kilometers. Further, glyoxal is the most soluble molecule in Table 1; i.e., its Henry's law constant is 2000, 13860, and 30000 times larger than that of the other oxygenated hydrocarbons (OVOC) methanol, acetone, and acetaldehyde, respectively. The differences in the physical and chemical properties have fundamental implications for the air-sea exchange of glyoxal. For example, while it is possible to supersaturate the surface ocean with acetaldehyde (Zhou and Mopper, 1990; Kieber et al., 1990; Millet et al., 2010; Yang et al., 2014), it is impossible to supersaturate the ocean with glyoxal (Sinreich et al., 2010). Studies measuring the waterside concentration of glyoxal have values in the nanomolar (nM) range (Zhou and Mopper, 1990: 0.5-5 nM; van Pinxteren and Herrmann, 2013): $\sim 4 \mathrm{nM}$ ), while based on $K_{\mathrm{H} \text {,glyoxal }}$ and an airside $\mathrm{VMR}$ of 50 pptv the expected seawater concentration should be $\sim 20000 \mathrm{nM}$. The low glyoxal abundance in the MBL and unique properties make glyoxal a particularly interesting, yet challenging, molecule to measure EC fluxes. To the best of our knowledge there have been no previous attempts to measure EC fluxes of glyoxal.

Glyoxal, the smallest $\alpha$-dicarbonyl, is largely produced from the oxidation of volatile organic compounds (VOCs) of both natural and anthropogenic origins (Myriokefalitakis et al., 2008; Stavrakou et al., 2009). It can also be directly emitted from sources such as biomass burning and fossil and biofuel combustion (Grosjean et al., 2001; Kean et al., 2001; Hays et al., 2002). Atmospheric removal of glyoxal is driven by photolysis, reaction with hydroxyl $(\mathrm{OH})$ radicals, dry and wet deposition, and uptake to aerosols (Stavrakou et al., 2009). Additionally, glyoxal has been identified as an important secondary organic aerosol (SOA) precursor (Liggio et al., 2005; Volkamer et al., 2007; Fu et al., 2008; Ervens and Volkamer 2010; Waxman et al., 2013). There are currently only few reports of glyoxal measurements over oceans (Zhou and Mopper, 1990; Sinreich et al., 2010; Mahajan et al., 2014). These data show significant variability in the abundance of glyoxal (25-140 pptv) and confirm the widespread presence of glyoxal over oceans that had been suggested by satellites (Wittrock et al., 2006; Lerot et al., 2010). Satellites find vertical column densities (VCDs) of $2-4 \times 10^{14}$ molecules $\mathrm{cm}^{-2}$ over the eastern Pacific Ocean, comparable to and exceeding the upper range of glyoxal mixing ratios observed in the MBL (assuming all glyoxal was located inside a $1 \mathrm{~km}$ high MBL). In situ observations hold great potential to inform this apparent mismatch, but there are no previous in situ measurements of glyoxal reported over oceans. While virtually all measurements of glyoxal have been made over land (Vrekoussis et al., 2009), our understanding of the sources, sinks, and chemical processing of this molecule in continental air masses remains poor. Known continental sources only account for $\sim 50 \%$ of the glyoxal budget based on VCDs from the SCanning 
Table 1. Overview of eddy covariance flux measurements from ships.

\begin{tabular}{lrrrl}
\hline Molecule & $\begin{array}{r}\text { MBL concentration } \\
(\mathrm{pptv})\end{array}$ & $\begin{array}{r}K_{\mathrm{H}} \\
\left(\mathrm{M} \mathrm{atm}^{-1}\right)\end{array}$ & $\begin{array}{r}\text { Lifetime* } \\
(\text { days })\end{array}$ & $\begin{array}{l}\text { Reference flux } \\
\text { measurement in MBL }\end{array}$ \\
\hline $\mathrm{CO}_{2}$ & $380-400\left(\times 10^{6}\right)$ & 0.035 & $>3 \times 10^{5}$ & Fairall et al. (2000) \\
$\mathrm{CO}$ & $60-150\left(\times 10^{3}\right)$ & $1 \times 10^{-3}$ & 16 & Blomquist et al. (2012) \\
Acetone & $700-900$ & 30.3 & 10 & Marandino et al. (2005) \\
$\mathrm{O}_{3}$ & $10-30\left(\times 10^{3}\right)$ & 0.011 & 6 & Bariteau et al. (2010) \\
Methanol & $300-900$ & 222 & 4 & Yang et al. (2013) \\
DMS & $20-1500$ & 0.485 & 0.8 & Hubert et al. (2004) \\
Acetaldehyde & $200-300$ & 14.1 & 0.2 & Yang et al. (2014) \\
Glyoxal & $25-80$ & $4.2 \times 10^{5}$ & $9 \times 10^{-2}$ & This work \\
\hline
\end{tabular}

* Lifetimes calculated against reaction with $\mathrm{OH}$ (assuming $[\mathrm{OH}]=3 \times 10^{6}$ molecules $\mathrm{cm}^{-3}$ ), and photolysis rates calculated for aerosol-free, noontime-at-Equator conditions.

Imaging Absorption spectroMeter for Atmospheric CHartographY (SCIAMACHY) satellite (Stavrakou et al., 2009). Over the tropical ocean, atmospheric models predict virtually no glyoxal (Myriokefalitakis et al., 2008; Fu et al., 2008; Stavrakou et al., 2009); the presence of this molecule in the remote MBL, thousands of kilometers from continental sources, is surprising and currently not understood (Sinreich et al., 2010).

The University of Colorado Fast Light-Emitting Diode Cavity-Enhanced Differential Optical Absorption Spectroscopy (Fast LED-CE-DOAS) instrument was developed to obtain new insights about the sources of glyoxal in the remote MBL. The following sections describe the instrument, characterize performance, and report first results from a ship deployment over the tropical eastern Pacific Ocean during the Tropical Ocean tRoposphere Exchange of Reactive halogens and Oxygenated VOCs (TORERO) field experiment.

\section{Experimental}

The TORERO 2012 field campaign was an extensive effort to measure a variety of atmospheric parameters and trace gases over the eastern tropical Pacific Ocean from aircraft and ships. The ship-based portion of the campaign took place aboard the NOAA RV Ka'imimoana on a research cruise leaving from Honolulu, HI, to Puntarenas, Costa Rica, between 25 January and 1 March 2012 (37 days at sea). Figure 1 shows a map with the ship track. Also shown are HYSPLIT 5-day back trajectories for noon and midnight (local time) along the ship track for each day.

\subsection{Fast LED-CE-DOAS instrument}

Differential optical absorption spectroscopy (DOAS) is a well-established technique that has been successfully used to measure a wide variety of atmospheric trace gases, including glyoxal (Platt, 1994). While traditionally DOAS measurements were conducted in the open atmosphere (Platt et al.,

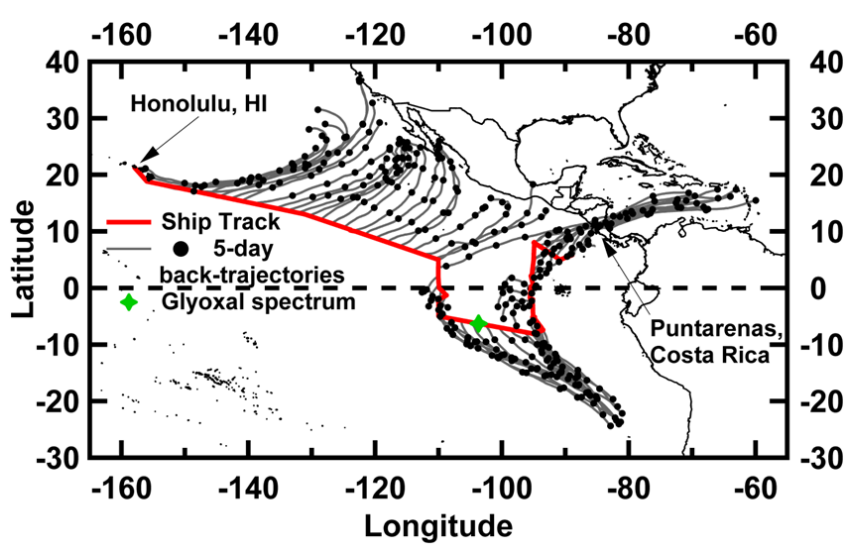

Figure 1. Cruise track of the NOAA RV Ka'imimoana during the TORERO 2012 field experiment (red trace). The ship set sail from Honolulu, HI, on 25 January 2012 and made final port in Puntarenas, Costa Rica, on 1 March 2012 (37 days at sea). Shown along the ship track are HYSPLIT 5-day back trajectories (initiated at 00:00 and 12:00 LT every day; solid grey lines). The black circles along the trajectories are spaced by 1 day. Air sampled in the Northern Hemisphere had been over the ocean for at least 2 days prior to reaching the ship and often did not experience land influences for at least 5 days. Air sampled in the Southern Hemisphere had been over the ocean for more than 5 days without obvious land/pollution influences. The location of the example glyoxal spectrum is marked by the green star.

1979), the advent of CEAS measurements coupled with DOAS retrievals has provided particularly sensitive measurements (Thalman and Volkamer, 2010; Ryerson et al., 2013). The multispectral nature of the light sources, such as light-emitting diodes (LEDs), add selectivity to enable the simultaneous detection of multiple trace gases, while preserving excellent sensitivity found in other in situ cavityenhanced techniques (e.g., cavity ring-down spectroscopy) (Thalman and Volkamer, 2010; Ryerson et al., 2013). The Fast LED-CE-DOAS instrument is a further development of the instrument described in Thalman and Volkamer (2010). 


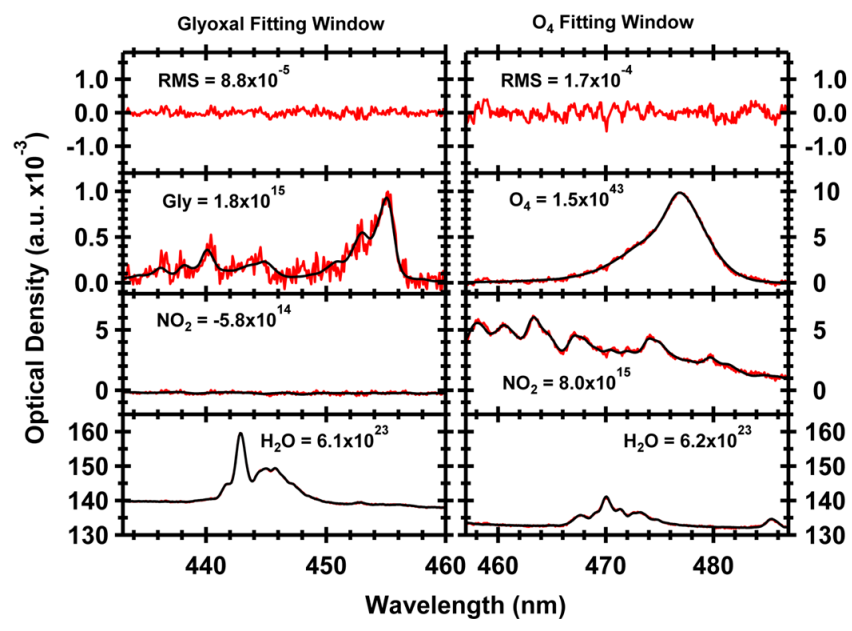

Figure 2. Example spectra of molecules measured by the Fast LED-CE-DOAS instrument. The DOAS fits are shown for glyoxal (left panel, 433-460 nm fit window), $\mathrm{O}_{4}$ and $\mathrm{NO}_{2}$ (right panel, $457-487 \mathrm{~nm}$ ), and water vapor (both windows). The RMS residual for each fit is shown in the top row. The spectra shown here were recorded on 14 February 2012 at $\sim 06: 20 \mathrm{LT}$ (glyoxal) and 11 February 2012 at $\sim 13: 40 \mathrm{LT}\left(\mathrm{O}_{4}\right)$. The corresponding slant column density for each trace gas is also given in units of molecules $\mathrm{cm}^{-2}$, except $\mathrm{O}_{4}$, which has units of molecules ${ }^{2} \mathrm{~cm}^{-5}$.

In brief, an LED light source is coupled to an optical cavity enclosed by two highly reflective mirrors, which allows light paths inside the cavity to be realized that are much longer $\left(\sim 2 \times 10^{4}\right.$ times) than the length of the cavity itself. The light is collected from the backside of the mirror opposite the LED by an optical fiber and directed onto the spectrometer slit (see Fig. 4).

For this system, a high-power LED (LedEngin model number LZ1-00B205; peak optical power $1.3 \mathrm{~W}$ ) with peak emission near $465 \mathrm{~nm}$ was used in conjunction with custom coated mirrors (Advanced Thin Films) with peak reflectivity between 440 and $470 \mathrm{~nm}$. The cavity had a base length of $86 \mathrm{~cm}(74.45 \mathrm{~cm}$ sample path length) and was coupled to a Princeton Instruments Acton SP2156 Czerny-Turner imaging spectrometer with a PIXIS 400B CCD (charge-coupled device) detector $(1340 \times 400$ pixels or $26.8 \times 8 \mathrm{~mm})$. The spectrometer utilized a custom $1000 \mathrm{~g} \mathrm{~mm}^{-1}$ grating blazed at $250 \mathrm{~nm}$ which covered the wavelength range of 390$530 \mathrm{~nm}$ with $\sim 0.75 \mathrm{~nm}$ resolution (full width at half maximum, or FWHM).

The wavelength range observed simultaneously by our system was from 430 to $480 \mathrm{~nm}$ and allowed for the selective detection of glyoxal, $\mathrm{NO}_{2}, \mathrm{H}_{2} \mathrm{O}$, and $\mathrm{O}_{4}$. Two spectral fitting windows were utilized during this study: one optimized for the retrieval of glyoxal and the other for $\mathrm{O}_{4}$. The glyoxal fitting window covered the wavelength range of $433-460 \mathrm{~nm}$; the $\mathrm{O}_{4}$ window covered the range $457-487 \mathrm{~nm}$; and trace gas reference cross sections for glyoxal (Volkamer et al., 2005), $\mathrm{H}_{2} \mathrm{O}$ (measured with this instrument), $\mathrm{O}_{4}$

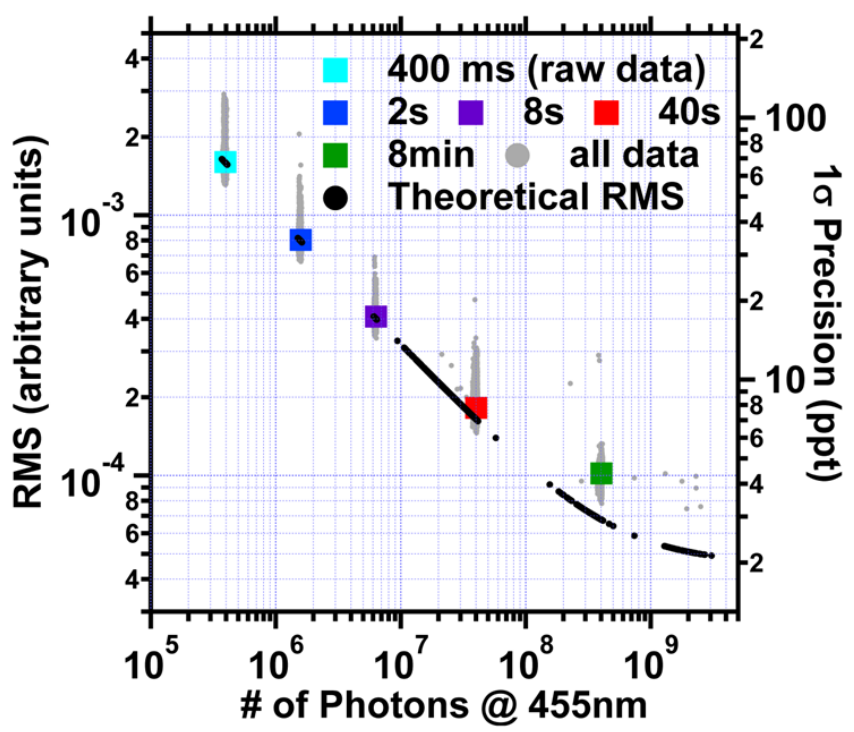

Figure 3. Fast LED-CE-DOAS instrument performance: sensitivity. The residual noise (RMS) from the DOAS analysis is shown as a function of the number of photons corresponding to different averaging of the data. Grey points represent all data, while colored squares represent their respective mean value; black circles represent the theoretical RMS value determined from photon-counting statistics (Coburn et al., 2011). The corresponding $1 \sigma$ precision of glyoxal is plotted on the right axis.

(Thalman and Volkamer, 2013), and $\mathrm{NO}_{2}$ (Vandaele et al., 1998) were simultaneously fitted in both windows. Figure 2 shows spectral fit results from the DOAS analysis of these trace gases: the left column shows fits from the glyoxal analysis window for a clean period (no $\mathrm{NO}_{2}$ contamination from the ship stack), and the right column shows spectral fits from the $\mathrm{O}_{4}$ window where some $\mathrm{NO}_{2}$ contamination is present. The water measurement was used to monitor ambient conditions, $\mathrm{NO}_{2}$ was used as a tracer for sampling the ship stack plume, and the $\mathrm{O}_{4}$ measurement was used to correct the DOAS data for sampling time lag and inlet characterization (discussed in Sects. 3.1.1 and 3.1.2).

The primary measurement of the DOAS technique is slant column density (SCD), which is the integrated concentration of the measured species along all light paths. It is easily converted using Lambert-Beer's law to concentration if the light path length within the cavity is known. Two different methods were utilized to experimentally determine the cavity light path: (1) comparison of measured $\mathrm{O}_{4}$ SCDs and the calculated concentration of $\mathrm{O}_{4}$ within the cavity, and (2) using the ratio of the signal measured in two different pure gases whose Rayleigh scattering cross sections are well known (Thalman and Volkamer, 2010). For this study, method 2 was employed and $\mathrm{N}_{2}$ and $\mathrm{He}$ were used for this process (referred to as mirror curves from this point forward). Mirror curves were taken on a near daily basis, which enabled the continuous monitoring of the cavity performance. Additionally, 
an inherent consistency check exists from the comparison of $\mathrm{O}_{4} \mathrm{SCD}$ measurements with those calculated from the mirror curve, the Rayleigh scattering cross section of air, and known temperature and pressure (Thalman and Volkamer, 2010). For the duration of the cruise, the peak mirror reflectivity was maintained between 99.9967 and $99.9973 \%$, translating into routine cavity path lengths of $18-20 \mathrm{~km}$ at $455 \mathrm{~nm}$.

In order to accelerate the data acquisition of the instrument to rates sufficient to accommodate EC fluxes, software was developed to simultaneously eliminate shutter movements and decrease readout time (through binning of CCD rows). The final instrument measurement frequency of $\sim 2 \mathrm{~Hz}$ strikes a balance between time resolution and the duty cycle dedicated to collecting photons (as compared to readout time of the $\mathrm{CCD}$ ). The measurement detection limit with CE-DOAS measurements is typically photon shotnoise-limited. We assess the instrument performance by investigating the root mean square (RMS) of the optical density of the residual remaining after the nonlinear least squares fitting routine and by comparing it with the theoretical photon shot noise (Coburn et al., 2011). Individual spectra were summed and analyzed to improve the signal-to-noise ratio of the measurements. In an ideal instrument (i.e., completely limited by photo shot noise), the RMS of the fitting routine should follow photon-counting statistics, where the theoretical RMS is inversely proportional to the square root of the number of photons collected.

$\mathrm{RMS} \equiv \frac{1}{\sqrt{N}}$,

where $N$ is the number of photons collected.

The measured RMS of the Fast LED-CE-DOAS instrument field deployment is compared to the theoretical RMS and plotted as a function of the number of photons in Fig. 3. The grey points are raw data at different levels of averaging, and the colored squares represent the median values for each set: light blue is the raw $400 \mathrm{~ms}$ data; dark blue is the sum of 5 spectra $(\sim 2 \mathrm{~s})$; purple is the sum of 20 spectra $(\sim 8 \mathrm{~s})$; red is the sum of 100 spectra $(\sim 40 \mathrm{~s})$; and the green is the sum of 1000 spectra ( $\sim 8 \mathrm{~min})$. As can be seen, the RMS during this campaign fairly closely follows counting statistics for the measured spectra, as well as for different levels of binning. Shown on the right axis is the corresponding $1 \sigma$ precision for glyoxal.

Appropriate quality assurance filters were applied to the raw CE-DOAS measurements prior to calculating glyoxal fluxes in order to exclude the use of any stack contamination, or otherwise questionable data. These filters removed periods of elevated $\mathrm{NO}_{2}$ (contaminated by the ship stack plume: values greater than $\sim 30 \mathrm{pptv})$, instability in the cavity $\left(\mathrm{O}_{4}\right.$ and internal cavity pressure measurements: acceptable pressure range 470-500 torr) and any spectra where the DOAS fitting resulted in RMS values larger than $5 \times 10^{-3}$.

\subsection{TORERO field campaign}

While the cruise started on 25 January 2012, only data taken during 2 and 28 February 2012 will be considered for this study. The inlet for the cavity was mounted near the top of a $10 \mathrm{~m}$ jack staff $(18 \mathrm{~m}$ above sea level, a.s.l.) on the bow along with the inlets for the $\mathrm{CO}_{2}$ flux system (Blomquist et al., 2014) and the in situ $\mathrm{O}_{3}$ monitor, the sonic anemometer, and a motion system. The sampling line between the inlet and the instrument was $\sim 65 \mathrm{~m}$ long and consisted of $3 / 8$ in. inside-diameter coated aluminum tubing (Eaton SynFlex Type 1300). Additionally, an aerosol filter (changed every other day) was included after the inlet in order to prevent collection of sea salt in the sampling line and to keep the air reaching the CE-DOAS system aerosol-free. The filter was regularly changed to avoid aerosol accumulation, and experiments of glyoxal transfer through Teflon filters showed no visible attenuation (Thalman and Volkamer, 2010). In order to maintain turbulent flow throughout the sampling line, a high-flow pump maintained a flow of $\sim 120 \mathrm{~L} \mathrm{~min}^{-1}$ (Lenschow and Raupach, 1991). From this main flow, a sample flow of $\sim 9 \mathrm{~L} \mathrm{~min}^{-1}$ was pulled through the cavity. These flow conditions resulted in an operating pressure inside the cavity of $\sim 470-500$ torr. This sub-ambient cavity pressure had to be actively addressed due to the sensitivity of optical cavities to fluctuations in pressure (which can de-align the mirrors). This was accomplished by the addition of stabilizing mounts for the mirrors to prevent movement during measurements. Figure 4 contains a plumbing diagram for the CE-DOAS system, with arrows indicating the direction of air flow at various points along the sampling line. Two pumps and three mass flow controllers (MFCs) were used in this system: the main flow through the sampling line was set at $\sim 120 \mathrm{~L} \mathrm{~min}^{-1}$ (controlled by MFC 1), the smaller sample flow through the cavity was set at $\sim 9 \mathrm{~L} \mathrm{~min}^{-1}$ (controlled by MFC 2), and the calibration gases for the Fast LED-CEDOAS system (used for monitoring cavity performance and determining cavity path length) were controlled by MFC 3 . Photographs of the inlet, operational cavity, and instrument rack containing all controlling electronics and spectrometer can be found in Fig. S1 in the Supplement.

\section{Results}

\subsection{Instrument characterization}

The following sections will describe the characterization of instrument properties pertinent to the measurement of fluxes via the EC technique.

\subsubsection{Phase correction $\left(\mathrm{N}_{2}\right.$ pulse $)$}

Wind sensor data were collected at $10 \mathrm{~Hz}$, and in order to calculate the glyoxal fluxes the CE-DOAS measurements needed to be synchronized to these data. Rather than 


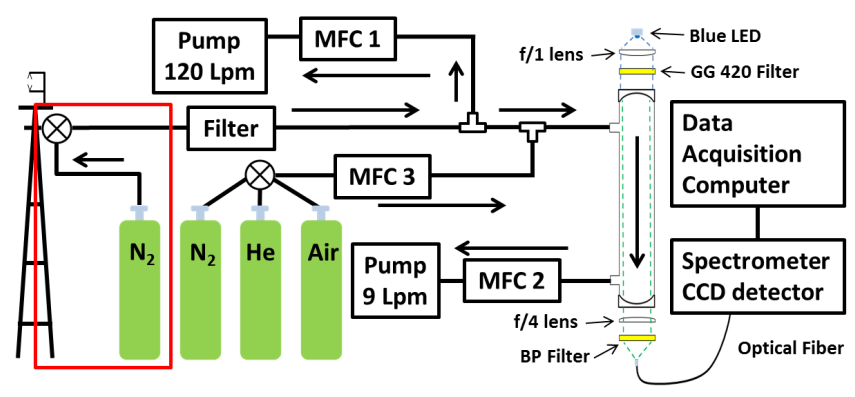

Figure 4. Sketch of the Fast LED-CE-DOAS setup and plumbing diagram for sampling during TORERO 2012. The $\mathrm{N}_{2}$ "puff" system is indicated by the red box, and a graphic of the sonic anemometer is shown at the top of the tower. Arrows show the direction of flow through various portions of the system. Photographs of this setup can be found in Fig. S1. The bandpass (BP) and GG 420 filters are used to further narrow the wavelength range of light reaching the spectrometer to that around the peak reflectivity of the mirrors. The lenses utilized in this setup were selected based the incident light and the space allocated for the optics, necessitating the use of both $f / 1$ and $f / 4$ focal length lenses. MFC: mass flow controller.

degrading the high resolution wind data, the CE-DOAS measurements were first interpolated from 2 to $10 \mathrm{~Hz}$. Since the trace gas is drawn through an inlet, there is a finite time difference between the instantaneous wind velocity measurements and those of the trace gas measurements. The flux system deployed here includes a method for experimentally determining this correction. The method is described in detail in Bariteau et al. (2010), so only a brief overview will be given here: the inlet is equipped with a fast-switching solenoid valve that injects pure nitrogen (supplied from a compressed air cylinder) into the sample flow. The valve is triggered for $3-5 \mathrm{~s}$ at the beginning of every hour, and the signal used as the trigger is recorded on the same timestamp as the anemometer. These data are used in conjunction with the accompanied drop in the trace gas signal (recorded on a different timestamp) to continuously monitor and apply a correction to the timestamps prior to correlating both sensors. In the cavity, the measurement of $\mathrm{O}_{4}$ was used for this correction. Figure 5 contains a plot showing an example of the corrected $\mathrm{O}_{4}$ signal overlaid on the nitrogen pulse signal (black trace); also shown is the fit of the step response function from method 1 (blue trace; see below). The raw $\mathrm{O}_{4}$ measurements are shown as black circles, and the interpolated data are the smaller red circles. Two methods were used to determine the phase correction based on the drop in the $\mathrm{O}_{4}$ signal: (1) fitting of a first-order step response function (2) and manual determination. Method 2 involved using $\mathrm{O}_{4}$ data averages to identify when the $\mathrm{N}_{2}$ was attenuating the $\mathrm{O}_{4}$ signal, and from there to determining the time at which the signal actually started dropping. Each analysis was performed on hourly data files; 626 files were analyzed, and 50 of these files did not meet basic criteria to enable the pulse matching and so were rejected; the total number of usable hours for the

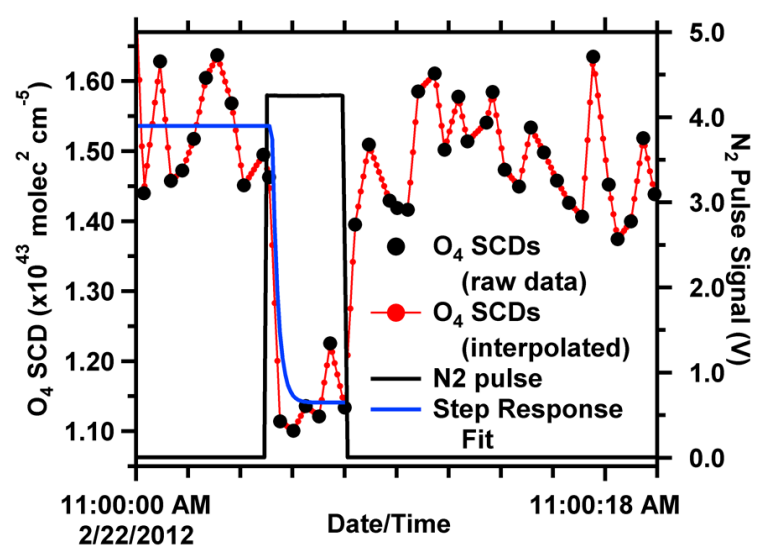

Figure 5. Illustration of the phase correction and time response using $\mathrm{O}_{4}$. Individual CE-DOAS $\mathrm{O}_{4}$ measurements (black dots) were interpolated onto the timestamp of the wind sensor (red dots). The $\mathrm{N}_{2}$ pulse signal (solid black line) is visible as the drop in $\mathrm{O}_{4} \mathrm{SCDs}$; the data have already been time-shifted to match this $\mathrm{N}_{2}$ trigger. Also shown is the fit of a step response function (solid blue line) to the drop in the $\mathrm{O}_{4}$ signal, from which an instrument time response can be determined.

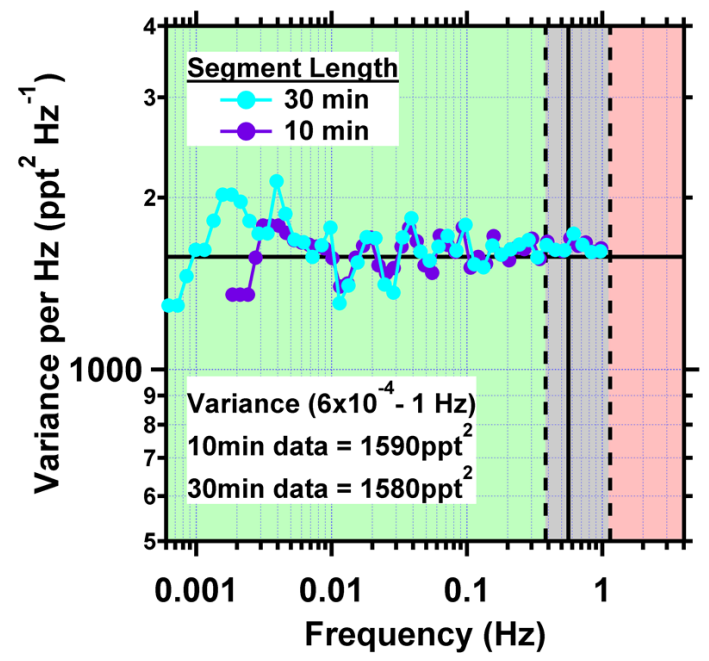

Figure 6. Fast LED-CE-DOAS instrument performance: frequency response for glyoxal. The glyoxal variance distribution per frequency bin is for a $6 \mathrm{~h}$ section of data (representative of the global average) on 4 February 2012 from 06:00 to 12:00 LT. The horizontal line represents the integral variance $\left(\sim 1600 \mathrm{ppt}^{2} \mathrm{~Hz}^{-1}\right)$ at frequencies measured by the instrument (green shading). The solid vertical line represents the cutoff frequency determined from the average time response of the instrument; the dashed vertical lines represent the standard deviation of the time response data (grey background shading); higher frequencies were not measured by our setup (red shading). The Nyquist frequency of our setup is $1 \mathrm{~Hz}$.

flux data was 576. The average difference found between the two phase correction methods was $0.11 \mathrm{~s}$, and the statistics associated with each analysis can be found in Table 2 . 


\subsubsection{Response time}

The pulse of nitrogen described in the previous section was also used to characterize the response time of the instrument. Introducing pure $\mathrm{N}_{2}$ gas into the sample flow created a drop in the $\mathrm{O}_{4}$ signal, which was exploited to determine the response time of the instrument. The same two methods employed for the phase correction were used to calculate the instrument response time, which also gave an average difference between methods of $0.11 \mathrm{~s}$ (statistics in Table 2). The instrument response is best determined experimentally, since high-frequency flux attenuations can be caused by drawing the sample through the aerosol filter and long sampling line. Here, a low-pass filter function was chosen to represent the attenuation.

$H(f)=\frac{1}{1+\left(2 \pi f \tau_{c}\right)^{2}}$,

where $\tau_{c}$ is the instrument response time.

Using the measured response time and the filter function, the instrument cutoff frequency $\left(F_{\mathrm{c}}\right)$ (the frequency at which the signal fluctuations drop by $1 / \sqrt{ } 2$ ) was calculated, which corresponds to a drop in the signal to 0.5 .

$F_{\mathrm{c}}=\frac{1}{2 \pi \tau_{c}}$

Using the average values of the response time of 0.283 and $0.282 \mathrm{~s}$ for the first-order step response function and the manual determination, respectively, the calculated cutoff frequency is $0.56 \mathrm{~Hz}$. The application of the filter function for this system and the effect of the response time on the highfrequency attenuation will be discussed in Sect. 3.3.1. These small differences in response time determined from the two methods add certainty about the correction of the flux measurements, as is discussed in more detail in Sect. 3.3.3.

\subsubsection{Fast measurements}

The variance spectra for glyoxal as a function of frequency for a $6 \mathrm{~h}$ time period on 4 February 2012 from 06:00 to 12:00 LT are shown in Fig. 6. Data from both $10 \mathrm{~min}$ (purple) and $30 \mathrm{~min}$ (light blue) averaging periods (see Sect. 3.3.2) are included in this plot.

The constant variance per $\mathrm{Hz}$ in the frequency range sampled by the instrument demonstrates that the Fast LED-CEDOAS system is indeed a white-noise sensor. The horizontal black line represents the integral of the data in the frequency range $6 \times 10^{-4}$ to $1 \mathrm{~Hz}$ of $\sim 1585 \mathrm{pptv}^{2}$. The solid vertical black line depicts the cutoff frequency of the instrument calculated from the average response time of the instrument, and the dashed vertical black lines represent \pm 1 standard deviation of these data.

\subsection{Diurnal cycle measurements}

Analyzing data created from summing 1000 spectra $(\sim 8 \mathrm{~min}$ total integration time) enabled the measurement of a diurnal cycle of glyoxal between 2-28 February 2012. A time series of these measurements can be found in Fig. 7 (top panel, left axis). Summing 1000 spectra allowed the realization of an average RMS value of $(1.0 \pm 0.1) \times 10^{-4}$, which translates into an average detection limit of $5.9 \mathrm{pptv}$ over $8 \mathrm{~min}$; lower detection limits are possible from further averaging of the data. Figure 3 indicates that the reduction in the achievable 1- $\sigma$ precision follows the theoretical RMS over several minutes, and becomes limited by the photon shot noise of the reference spectrum at longer times (rolling-off in the "theoretical RMS" trace). In the absence of this reference-noise limitation, a photon count over $1 \mathrm{~h}\left(3 \times 10^{9}\right.$ photons $)$ corresponds to an extrapolated $1-\sigma$ precision of $0.8 \mathrm{pptv}$, and a 3 $\sigma$ detection limit $(1 \mathrm{~h})$ of $\sim 2.4 \mathrm{pptv}$ glyoxal. If, instead, the detection limit is calculated based on averaging the statistical variability of the VMR data, the 3- $\sigma$ detection limit $(1 \mathrm{~h})$ is $\sim 2.2 \mathrm{pptv}$. This sensitivity is needed to resolve the small changes in the diurnal variation of glyoxal shown in Fig. 7. Also shown are time traces for in situ $\mathrm{O}_{3}$, solar zenith angle (SZA), $\mathrm{NO}_{2}, \mathrm{RH}$, ambient air temperature, ambient pressure, wind speed (from the sonic anemometer), and a flag indicating periods that were suitable for EC fluxes. Figure S2 contains time traces of the parameters used to determine periods that were suitable to perform the EC flux calculations.

\subsection{Ambient flux measurements}

\subsubsection{Signal attenuation}

As introduced in Sect. 3.1.2, a low-pass filter function was used to assess the high-frequency flux attenuation due to the aerosol filter and sampling line length; Eq. (1) can be re-written as Eq. (5):

$$
\begin{aligned}
& F_{\mathrm{c}}=\overline{w^{\prime} c_{\mathrm{m}}^{\prime}}= \\
& \int_{0}^{f_{\mathrm{n}}} C_{\mathrm{wc}}(f)[H(f)]^{\frac{1}{2}} \mathrm{~d} f=\int_{0}^{f_{\mathrm{n}}} C_{\mathrm{wcm}}(f) \mathrm{d} f,
\end{aligned}
$$

where the subscript $\mathrm{m}$ represents the measured values; see Eq. (1) for other variables (note that the square root appears in the modified equation because only the signal of the trace gas is attenuated).

This relationship can then be used to assess the effect of attenuation on the overall flux by applying the filter function using the Kaimal model neutral-stability cospectrum (Kaimal et al., 1972), derived via Eqs. (6a) and (6b):

$$
\begin{aligned}
\frac{f C_{\mathrm{wc}(f)}}{F_{\mathrm{c}}} & =\frac{11 n}{(1+13.3 n)^{1.75}}, \quad n \leq 1.0 \\
\frac{f C_{\mathrm{wc}(f)}}{F_{\mathrm{c}}} & =\frac{4.4 n}{(1+3.8 n)^{2.4}}, \quad n \geq 1.0,
\end{aligned}
$$


Table 2. The average phase correction and time response of the Fast LED-CE-DOAS instrument (with standard deviation) for the two different methods employed in this study. See text for details.

\begin{tabular}{|c|c|c|c|c|}
\hline & \multicolumn{2}{|c|}{ Method 1} & \multicolumn{2}{|c|}{ Method 2} \\
\hline & $\begin{array}{r}\text { Phase } \\
\text { correction (s) }\end{array}$ & $\begin{array}{r}\text { Time } \\
\text { response }(\mathrm{s})\end{array}$ & $\begin{array}{r}\text { Phase } \\
\text { correction (s) }\end{array}$ & $\begin{array}{r}\text { Time } \\
\text { response (s) }\end{array}$ \\
\hline Average & -2.54 & 0.28 & -2.61 & 0.28 \\
\hline Standard deviation & 0.23 & 0.16 & 0.24 & 0.14 \\
\hline
\end{tabular}

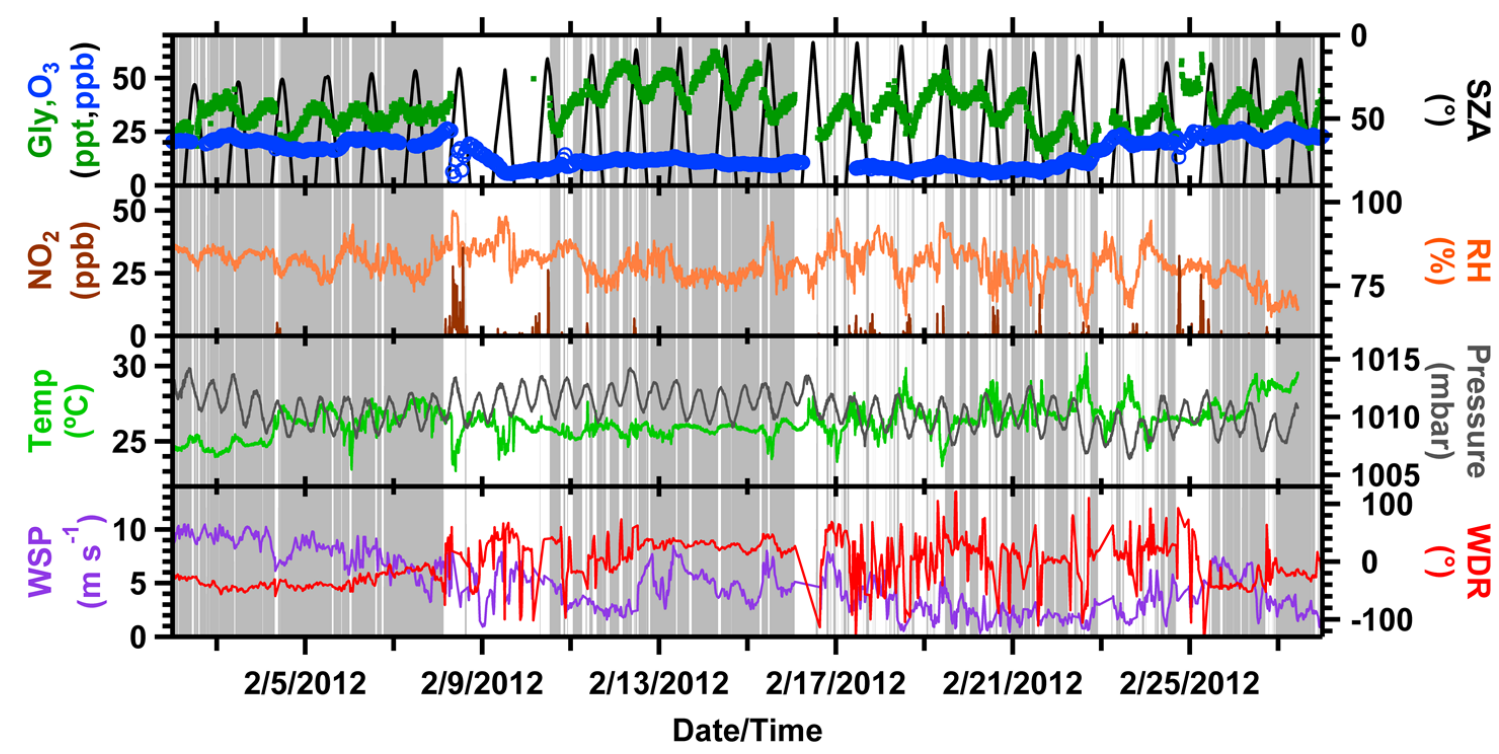

Figure 7. Time series of glyoxal, $\mathrm{O}_{3}$, and $\mathrm{NO}_{2}$, as well as meteorological parameters. Grey shaded background represents times suitable for flux calculations; filters included $\mathrm{NO}_{2}$, cavity pressure, wind direction, wind direction standard deviation, ship heading range, $\mathrm{d} G l y / \mathrm{d} t$, and the horizontal glyoxal flux components. See text and Fig. S2 for details.

where the surface normalized frequency $n=f z / \overline{u_{\mathrm{r}}}, z$ is the measurement height, and $\overline{u_{\mathrm{r}}}$ is the average relative wind speed. Using the calculated "true" and "measured" Kaimail cospectra, an attenuation ratio $\left(R_{\text {attn }}\right)$ was derived.

$$
\begin{aligned}
R_{\mathrm{attn}}\left(z, \overline{u_{\mathrm{r}}}\right)= & \frac{\int_{0}^{f_{\mathrm{n}}} C_{\mathrm{wc} \_\mathrm{K}}\left(f, z, \overline{u_{\mathrm{r}}}\right)[H(f)]^{\frac{1}{2}} \mathrm{~d} f}{\int_{0}^{f_{\mathrm{n}}} C_{\mathrm{wc} \_\mathrm{K}}\left(f, z, \overline{u_{\mathrm{r}}}\right) \mathrm{d} f} \\
= & \frac{\int_{0}^{f_{\mathrm{n}}} C_{\mathrm{wcm} \_\mathrm{K}}\left(f, z, \overline{u_{\mathrm{r}}}\right) \mathrm{d} f}{\int_{0}^{f_{\mathrm{n}}} C_{\mathrm{wc} \_\mathrm{K}}\left(f, z, \overline{u_{\mathrm{r}}}\right) \mathrm{d} f} \\
= & \frac{\int_{0}^{f_{\mathrm{n}}} C_{\mathrm{wcm}}\left(f, z, \overline{u_{\mathrm{r}}}\right) \mathrm{d} f}{\int_{0}^{f_{\mathrm{n}}} C_{\mathrm{wc}}\left(f, z, \overline{u_{\mathrm{r}}}\right) \mathrm{d} f}=\frac{F_{x \mathrm{~m}}}{F_{x}},
\end{aligned}
$$

where $C_{\mathrm{wc} \_\mathrm{K}}$ denotes the Kaimal cospectrum. For the calculation of this ratio, the average value of $0.282 \mathrm{~s}$ for the instrument response time was used in the filter response function $H(f)$. The assessment of these data leads to an average attenuation ratio of 0.947 but never resulted in more than a $10 \%$ correction.

\subsubsection{Flux filtering and results}

Two different averaging periods for the glyoxal and vertical wind velocity data were used to determine the glyoxal flux: 10 and $30 \mathrm{~min}$, each segment containing a $50 \%$ overlap with following segments (11 segments per hour for $10 \mathrm{~min}$ data, and three segments per hour for $30 \mathrm{~min}$ data). Both averaging periods were used for the data derived from the two methods used for determining the phase correction, creating a total of four different flux data sets. Basic filtering criteria were applied to the averaged data segments to reject measurements from undesirable wind sectors $\left( \pm 60^{\circ}\right.$ relative wind direction and less than $10^{\circ}$ standard deviation) and excessive ship maneuvers (maximum $25^{\circ}$ heading range). Additional 


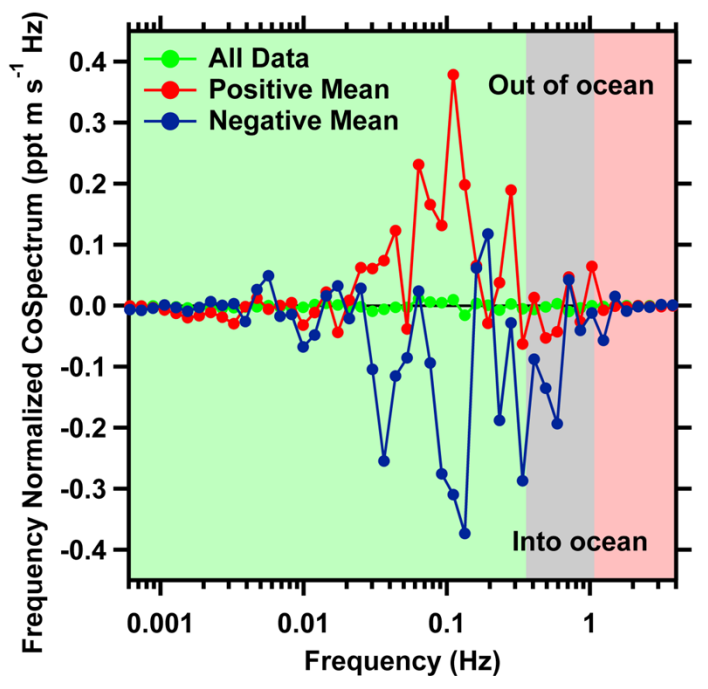

Figure 8. Cospectra of glyoxal and vertical wind from the flux calculations. The green trace represents the average of all cospectra that passed the quality assurance filters. The positive cospectrum (red) represents data averaged over a period of $\sim 3.5 \mathrm{~h}$ from 21:15 LT on 16 February 2012 to 00:45 LT on 17 February 2012. The negative cospectrum (blue) represents $\mathrm{a} \sim 1 \mathrm{~h}$ average on 2 February 2012 from 14:45 to 15:45 LT. The background color shading is identical to that in Fig. 6.

filtering criteria were applied to exclude outliers in the flux data through the assessment of the horizontal components of the glyoxal flux and the rate of change of glyoxal for each data segment. These filter values were chosen rather arbitrarily through a visual inspection of the data. No significant differences were found between the four data sets. Only results from the $30 \mathrm{~min}$ data determined from phase correction method 2 will be discussed. While individual flux measurements proved to be noisy, further binning of the $30 \mathrm{~min}$ flux measurements reveals trends in the data. Figure 8 contains example cospectra from these data, where the average of all data (green trace) scatters around zero. The examples of both positive (red trace) and negative (blue trace) cospectra were created by binning data: from 21:15 LT on 16 February to 00:45 LT on 17 February (positive cospectrum); and from 14:45 to 15:45 LT on 2 February (negative cospectrum).

\subsubsection{Error sources}

The potential sources of error in these data are (1) inaccuracies in determining the phase shift of the CE-DOAS measurements, (2) high-frequency signal loss due to sampling line attenuation, and (3) uncertainty surrounding the noisy raw glyoxal measurements. Phase shift determination was deemed to be rather robust (through the comparison of the values determined using the two different methods), and any small inaccuracies would have negligible effect on the flux data (as assessed by comparing the results from the four methods previously mentioned). The high-frequency flux loss due to signal attenuation was calculated as being, at most, $10 \%$ from the characterization in the instrument response time. Based on the cospectra (Fig. 8), it seems that glyoxal efficiently transferred through the sample lines and using the $\mathrm{O}_{4}$ measurements to characterize sample transfer is a justifiable assumption. Additionally, in the DOAS analysis there exists potential for cross correlations between water and glyoxal due to overlapping absorption features; however the most prominent absorption features are shifted and thus well separated (water: $\sim 443 \mathrm{~nm}$; glyoxal: $\sim 455 \mathrm{~nm}$ ). The effect of water on glyoxal retrievals was assessed in Thalman et al. (2014), where a very similar cavity-enhanced DOAS instrument was compared with numerous other techniques to measure alpha-dicarbonyls. The glyoxal retrieval is relatively insensitive to the presence of water. However, in order to rule out any effect of cross correlations in the glyoxal flux measurements, the eddy covariance flux method was applied to our water absorption data and water fluxes were derived in the same manner as that for the glyoxal measurements. Figure S3 contains correlation plots of glyoxal and water flux measurements, which show no distinct trends and indicate that the retrieval of glyoxal fluxes in this study is indeed insensitive to water absorption. While the glyoxal flux changes direction depending on time of day, the water flux is always positive, reflecting evaporation (see Sect. 4.2.2 and Fig. 10).

\section{Discussion}

\subsection{Volume mixing ratio measurements}

Volume mixing ratio data show a persistent diurnal trend: glyoxal mixing ratios peak just before dawn $(1 \mathrm{~h}$ average maximum in the NH: $43 \pm 2$ pptv; minimum: $26 \pm 1$ pptv; maximum SH: $61 \pm 1$ pptv; minimum: $39 \pm 2$ pptv), decrease during the day, and reach a minimum in the late evening just after dark ( $1 \mathrm{~h}$ average maximum in the $\mathrm{NH}: 36 \pm 1 \mathrm{pptv}$; minimum: $16 \pm 1 \mathrm{pptv}$; maximum SH: $48 \pm 2 \mathrm{pptv}$; minimum: $24 \pm 1 \mathrm{pptv}$ ), followed by continuous increase through the night. The day-to-day variability in glyoxal is significantly larger than the accuracy of our instrument. Major advantages with the Fast LED-CE-DOAS instrument to perform precise and accurate measurements of glyoxal are its inherent calibration from observing $\mathrm{O}_{4}$ (see above) as well as direct calibration from knowledge of the absorption cross section of glyoxal (Volkamer et al., 2005). An earlier prototype version of our instrument has undergone detailed comparison with a large variety of state-of-the-art glyoxal measurement techniques (Thalman et al., 2014). In short, these comparisons revealed an excellent performance; CE-DOAS was found to be both precise and accurate, with virtually negligible bias over a wide range of laboratory conditions. The ship measurements are deemed accurate to within 1-2 pptv glyoxal, or $3.5 \%$ at high signal-to-noise ratio, whichever is higher. This uncertainty in the measurements is smaller 


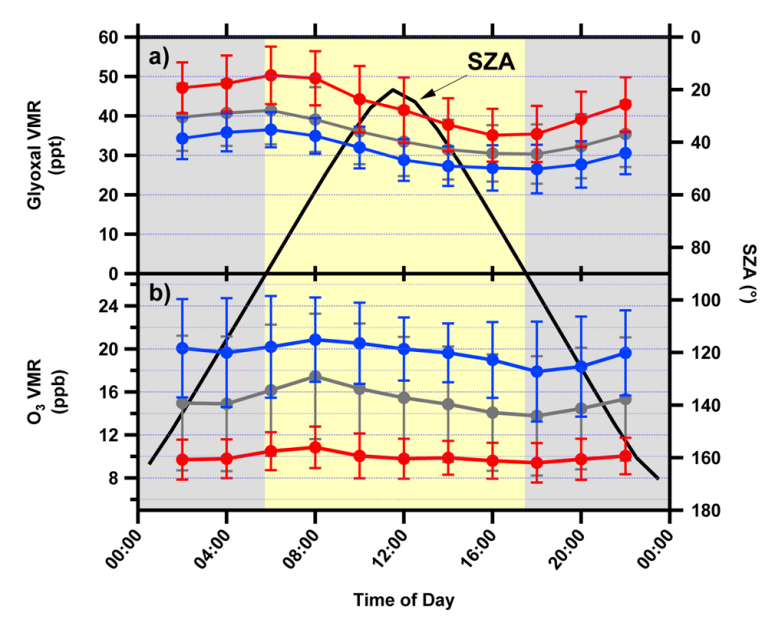

Figure 9. Diurnal variation in the glyoxal (a) and $\mathrm{O}_{3}$ mixing ratio (b) in the Northern (blue) and Southern Hemisphere (red). Only data that qualify for flux calculations have been averaged. Yellow shading indicates daytime, while grey indicates nighttime; the SZA is also shown on the right axis.

than that indicated by error bars, which are dominated (e.g., Fig. 9a) by the multiday variability in glyoxal over oceans. Indeed, the error bars for multiday averaged data reflect this variability (standard deviation), rather than the instrument precision/accuracy. Despite this significant day-to-day variability, some trends can be seen if data are segregated as a function of time of day (local time) and geographical location. Figure 9 shows the glyoxal VMR (panel a) and $\mathrm{O}_{3}$ VMR (panel b) binned as a function of time of day. The data were further segregated for measurements collected in the Northern Hemisphere (blue, $13^{\circ} \mathrm{N}$ to 0 ) and Southern Hemisphere (red, 0 to $10^{\circ} \mathrm{S}$ ); the global average of all data is shown as the grey trace. The number of data points within each bin is given in Table 3. The shaded regions in the background indicate daytime (yellow) and nighttime (grey), and the average SZA (minimum indicates solar noon) is further shown for reference on the right axis.

Given the nighttime increase in the glyoxal concentration that we observe in both hemispheres, $\mathrm{O}_{3}$ is the most likely oxidant of the glyoxal precursor. Interestingly, we observe about twice-higher $\mathrm{O}_{3}$ concentrations in the $\mathrm{NH}(\sim 20 \mathrm{ppbv}$ $\left.\mathrm{O}_{3}\right)$ than in the $\mathrm{SH}\left(\sim 10\right.$ ppbv $\left.\mathrm{O}_{3}\right) . \mathrm{O}_{3}$ does not reveal a significant diurnal cycle in either hemisphere, and the global campaign average $\mathrm{O}_{3}$ VMR is $\sim 15$ ppbv.

\subsection{Eddy covariance flux measurements}

\subsubsection{Glyoxal}

The diurnal variations in our glyoxal flux measurements (Fig. 10a) qualitatively reflect the variations in the VMRs seen in Fig. 9a. The error bars in Fig. 10 reflect the $90 \%$ confidence intervals of data within each bin. The maximum

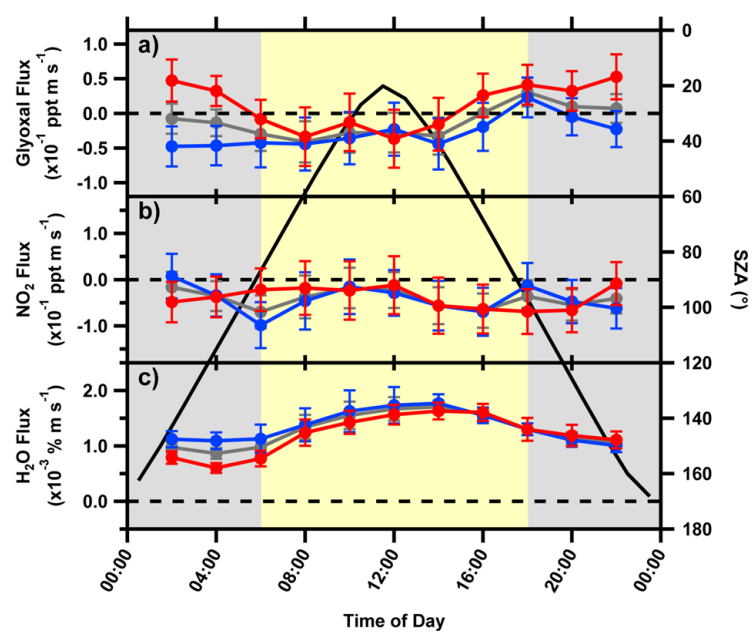

Figure 10. Diurnal variations in the fluxes of glyoxal (a), $\mathrm{NO}_{2}(\mathbf{b})$, and $\mathrm{H}_{2} \mathrm{O}(\mathbf{c})$. Data are separated between hemispheres, and the format here is the same as in Fig. 9.

fluxes are seen at night $\left(\mathrm{SH}:(5.3 \pm 3.3) \times 10^{-2} \mathrm{pptv} \mathrm{m} \mathrm{s}^{-1}\right.$; $\left.\mathrm{NH}:(2.3 \pm 3.1) \times 10^{-2} \mathrm{pptv} \mathrm{m} \mathrm{s}^{-1}\right)$ and minimum fluxes during the daytime $\left(\mathrm{SH}:(-1.6 \pm 3.8) \times 10^{-2} \mathrm{pptv} \mathrm{m} \mathrm{s}^{-1}\right.$; $\mathrm{NH}:(-5.6 \pm 4.1) \times 10^{-2}$ pptv $\left.\mathrm{m} \mathrm{s}^{-1}\right)$. All nighttime fluxes in the $\mathrm{SH}$ are significantly greater than zero ( $\mathrm{SH}$ nighttime average: $\left.(4.7 \pm 1.8) \times 10^{-2} \mathrm{pptv} \mathrm{m} \mathrm{s}^{-1}\right)$. The nighttime source of glyoxal from the ocean to the atmosphere is surprising, since glyoxal is so water soluble. Previous observations of positive fluxes of less-soluble OVOCs, such as acetaldehyde, have been attributed to supersaturation of subsurface waters in acetaldehyde (Zhou and Mopper, 1990; Yang et al., 2014). Glyoxal formation in subsurface waters cannot explain a positive flux to the atmosphere. This is because of the very large effective Henry's law coefficient $\left(K_{\mathrm{H}}=4.2 \times 10^{5} \mathrm{M} \mathrm{atm}^{-1}\right)$, which causes the equilibrium of glyoxal to be strongly shifted $\left(10^{7}: 1\right)$ towards the ocean (Volkamer et al., 2009). The high $K_{\mathrm{H}}$ value of glyoxal is the result of rapid hydration reactions; once hydrated, glyoxal exists primarily in mono- and di-hydrated forms (RuizMontoya and Rodriguez-Mellado, 1994, 1995) that give rise to the 3-5 orders of magnitude higher $K_{\mathrm{H}}$ value of glyoxal compared to other OVOCs (see Table 1). Ervens and Volkamer (2010) estimated the hydration rate of glyoxal to be $7 \mathrm{~s}^{-1}$. This corresponds to a lifetime of glyoxal with respect to hydrolysis of $\sim 140 \mathrm{~ms}$. Unless glyoxal escapes from the ocean within this time frame, it will hydrate and is trapped in hydrated forms in the condensed phase. Using Eq. (8)

$D=\frac{l^{2}}{2 t}$,

where $D$ is the diffusion coefficient (assuming a range $(0.001-1) \times 10^{-5} \mathrm{~cm}^{2} \mathrm{~s}^{-1}$; Finlayson-Pitts and Pitts, 2000), $l$ is distance, and $t$ is time, we estimate that the timescale of hydration of glyoxal corresponds to a diffusive length scale 
Table 3. Number of points in each time bin from Figs. 9 and 10.

\begin{tabular}{|c|c|c|c|c|c|c|}
\hline \multirow[b]{2}{*}{$\begin{array}{l}\text { Time } \\
\text { range }\end{array}$} & \multicolumn{3}{|c|}{ VMR data $\left(\right.$ Glyoxal/O $\left.{ }_{3}\right)$} & \multicolumn{3}{|c|}{ Flux data (Glyoxal/ $\left.\mathrm{NO}_{2} / \mathrm{H}_{2} \mathrm{O}\right)$} \\
\hline & All data & $\begin{array}{l}\text { Northern } \\
\text { Hemisphere }\end{array}$ & $\begin{array}{l}\text { Southern } \\
\text { Hemisphere }\end{array}$ & All data & $\begin{array}{l}\text { Northern } \\
\text { Hemisphere }\end{array}$ & $\begin{array}{l}\text { Southern } \\
\text { Hemisphere }\end{array}$ \\
\hline 00:00-04:00 & $494249 / 6154$ & $287844 / 3754$ & $206405 / 2400$ & $202 / 199 / 154$ & $117 / 114 / 86$ & $85 / 85 / 68$ \\
\hline 02:00-06:00 & $501180 / 6034$ & $302666 / 3750$ & $198514 / 2284$ & $203 / 200 / 159$ & $118 / 116 / 85$ & $85 / 84 / 74$ \\
\hline 04:00-08:00 & $465714 / 5930$ & $300299 / 3836$ & $165415 / 2094$ & $181 / 179 / 133$ & $114 / 112 / 77$ & $67 / 67 / 56$ \\
\hline 06:00-10:00 & $400277 / 5721$ & $286933 / 3677$ & $113344 / 2044$ & $146 / 138 / 102$ & $104 / 96 / 72$ & $42 / 42 / 30$ \\
\hline 08:00-12:00 & $412463 / 5398$ & $275280 / 3161$ & $137183 / 2237$ & $147 / 135 / 111$ & $98 / 88 / 70$ & $49 / 47 / 41$ \\
\hline $10: 00-14: 00$ & $457785 / 5367$ & $288476 / 2916$ & $169309 / 2451$ & $160 / 152 / 129$ & $103 / 96 / 79$ & $57 / 56 / 50$ \\
\hline $12: 00-16: 00$ & $495793 / 5545$ & $297908 / 3036$ & $197885 / 2509$ & $171 / 165 / 142$ & $102 / 98 / 80$ & $69 / 67 / 62$ \\
\hline 14:00-18:00 & $473626 / 5665$ & $262280 / 3163$ & $211346 / 2502$ & $174 / 171 / 142$ & $97 / 96 / 76$ & $77 / 75 / 66$ \\
\hline 16:00-20:00 & $450306 / 5845$ & $257819 / 3404$ & $192487 / 2441$ & $178 / 173 / 141$ & $106 / 101 / 83$ & $72 / 72 / 58$ \\
\hline $18: 00-22: 00$ & $486072 / 5984$ & $290658 / 3625$ & $195414 / 2359$ & $191 / 184 / 145$ & $116 / 110 / 83$ & $75 / 74 / 62$ \\
\hline 20:00-00:00 & $497257 / 6120$ & $302619 / 3780$ & $194638 / 2340$ & $193 / 190 / 151$ & $117 / 115 / 86$ & $76 / 75 / 65$ \\
\hline
\end{tabular}

of only $\sim 0.5-17 \mu \mathrm{m}$. Such a short distance rules out glyoxal production in sub-surface waters as a source for the positive glyoxal flux.

It is further unlikely that the observed nighttime positive flux could be attributed to gas-phase chemistry occurring below the measurement height but above the ocean surface. This is because we generally observe higher glyoxal fluxes and glyoxal VMRs in the $\mathrm{SH}$, where $\mathrm{O}_{3}$ is lower than in the $\mathrm{NH}$. The gradient in $\mathrm{O}_{3}$ between the two hemispheres is the reverse of that in glyoxal VMR. In principle, different precursors and mechanisms could form glyoxal in the two hemispheres. More likely, we interpret the reversed chemical gradients between both hemispheres to reflect the fact that the ocean is a net sink for $\mathrm{O}_{3}$ (Helmig et al., 2012); glyoxal is a product of the chemistry that destroys $\mathrm{O}_{3}$ at the ocean surface. Faster $\mathrm{O}_{3}$ destruction at the ocean surface in the $\mathrm{SH}$ (reflected in the lower observed $\mathrm{O}_{3}$ VMR) is thus compatible with the positive glyoxal fluxes, and higher glyoxal VMR, that we observe in the SH. Assuming a rather fast (upper limit) reaction rate constant for $\mathrm{O}_{3}$ to react with a glyoxal precursor in the gas phase $\left(k_{\mathrm{O}_{3}} \sim 10^{-15} \mathrm{~cm}^{3}\right.$ molecules ${ }^{-1} \mathrm{~s}^{-1}$; Atkinson et al., 2006), the corresponding precursor lifetime with respect to $\mathrm{O}_{3}$ reaction is about $45 \mathrm{~min}$ (assuming an average $\mathrm{O}_{3}$ VMR of $15 \mathrm{ppbv})$. Given that the glyoxal concentration increases through much of the night in both hemispheres (Fig. 9), the precursor that forms glyoxal at night is most likely longer lived (possibly a lifetime of several hours). Hence, any gasphase chemistry below our inlet is unlikely to be sufficiently fast to contribute much glyoxal over the $18 \mathrm{~m}$ distance from our inlet to the ocean surface. Furthermore, gas-phase chemistry below our inlet would produce glyoxal at a twice-higher rate in the $\mathrm{NH}$ compared to the $\mathrm{SH}$, while we see lowerglyoxal VMR in the $\mathrm{NH}$ and observe positive fluxes primarily in the SH. This evidence supports the assignment that the positive glyoxal fluxes observed at night locate a gly- oxal source inside the organic sea surface microlayer (SML). Chemistry within the SML is likely also a source of other OVOCs (e.g., formaldehyde, aliphatic and multifunctional aldehydes, methylglyoxal, etc.; Zhou and Mopper, 1990; Ayers et al., 1997; Zhou and Mopper, 1997; Zhou et al., 2014).

The maximum average positive (net) flux that we observe

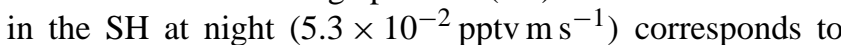
a primary glyoxal accumulation in a $800 \mathrm{~m}$ high $\mathrm{MBL}$ of about $\sim 2.5$ pptv over a period of $12 \mathrm{~h}$. This corresponds to $\sim 20 \%$ of the increase in the VMR of glyoxal that is actually being observed over the course of the night. We note that the EC technique measures a net flux, i.e., only the difference between deposition and emission fluxes. Based on the variability in the net flux, it appears that both processes are contributing to the signal. Given the rapid hydration reaction and high solubility of glyoxal, the fraction of the glyoxal molecules which deposit to the surface and are later re-emitted is likely small. We can assume that the deposition is essentially a $100 \%$ efficient sink and the emission we see is due to instantaneous production/emission within the SML that compensates for, and exceeds, the deposition flux. The actual surface production flux is the net flux corrected for the deposition flux. The daytime observed fluxes are significantly negative (NH daytime average: $(-4.6 \pm 2.3) \times 10^{-2}$ pptv $\left.\mathrm{m} \mathrm{s}^{-1}\right)$. Assuming a dry deposition velocity, $v_{\text {dep }}=1 \times 10^{-3} \mathrm{~m} \mathrm{~s}^{-1}$, and using the campaign average glyoxal VMR of $36 \mathrm{pptv}$ results in an estimated flux towards the ocean of $-3.6 \times 10^{-2} \mathrm{pptv} \mathrm{m} \mathrm{s}^{-1}$, which is within the error of the measurements. A larger deposition velocity, e.g., $7 \times 10^{-3} \mathrm{~m} \mathrm{~s}^{-1}$ (Yang et al., 2013), would correspond to a deposition flux of $-0.25 \mathrm{pptv} \mathrm{m} \mathrm{s}^{-1}$, which is compensated for by the SML production. A SML production flux of $\sim 0.3$ pptv m s${ }^{-1}$ is compatible with our data. A net production flux on this order is needed to explain the observed glyoxal VMR increase over night. However, the actual flux responsible for changes in the glyoxal VMR at night reflects 
the balance between production and deposition fluxes, which are likely operative and significant at night. The observed positive (net) fluxes cannot explain the observed increase in the glyoxal VMR at night by the SML source alone.

During the day the observed glyoxal flux is negative and indicates some unknown gas-phase source of glyoxal and likely other OVOCs in the MBL. While negative or neutral fluxes have also been observed for acetone and methanol (Marandino et al., 2005; Yang et al., 2013, 2014), both of these molecules live sufficiently long (acetone: 15 days; methanol: 13 days) for transport from the free troposphere (entrainment fluxes) and from terrestrial sources to likely contribute to their abundance in the remote MBL. By contrast, any glyoxal lost to the ocean has been produced locally. The daytime lifetime of glyoxal $(\sim 2 \mathrm{~h})$ is too short to explain this source in terms of transport from terrestrial sources. The lack of measurements of glyoxal vertical distributions over oceans in the literature complicates discussions of possible entrainment fluxes of glyoxal from the free troposphere. However, for purposes of this discussion any entrainment flux could help explain the negative net flux observed during the day, but cannot explain the positive net flux observed at night. We conclude that the SML is a significant source of glyoxal. However, the negative daytime net flux indicates deposition exceeds SML production during the day. A glyoxal source in the atmosphere is thus needed to sustain the elevated glyoxal VMR during the day, and currently remains unexplained. SML production alone appears insufficient to explain the glyoxal abundance and variation inside the MBL.

\subsection{2 $\mathrm{NO}_{2}, \mathrm{H}_{2} \mathrm{O}$, and $\mathrm{O}_{4}$ fluxes}

Absorption measurements of $\mathrm{NO}_{2}, \mathrm{H}_{2} \mathrm{O}$, and $\mathrm{O}_{4}$ by the Fast LED-CE-DOAS instrument are a by-product of processing the glyoxal data. The fluxes for these quantities were processed in the same fashion as the glyoxal fluxes, and diurnal profiles of $\mathrm{NO}_{2}$ and $\mathrm{H}_{2} \mathrm{O}$ fluxes are shown in Fig. 10. For $\mathrm{NO}_{2}$, the fluxes are smaller 0.05 pptv $\mathrm{NO}_{2} \mathrm{~m} \mathrm{~s}^{-1}$, and no evidence for a $\mathrm{NO}_{2}$ flux diurnal cycle is observed (Fig. 10b). This is consistent with the idea that $\mathrm{NO}_{2}$ is not directly emitted from oceans (Logan, 1983). The median global average

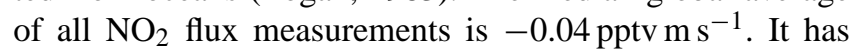
been shown that nitrogen oxide (NO) is photo-chemically produced by the ocean (Zafiriou et al., 1980; Zafiriou and McFarland, 1981; Olasehinde et al., 2010). $\mathrm{NO}_{2}$ is subsequently produced from the gas-phase reaction of $\mathrm{NO}$ with $\mathrm{O}_{3}$ $\left(k_{\mathrm{NO}, \mathrm{O}_{3}}=1.8 \times 10^{-14} \mathrm{~cm}^{3}\right.$ molecules ${ }^{-1} \mathrm{~s}^{-1}$; Atkinson et al., 1997). At 15 ppbv $\mathrm{O}_{3}$, this reaction converts $\mathrm{NO}$ into $\mathrm{NO}_{2}$ on a timescale of $\sim 2-3 \mathrm{~min}$. The absence of positive $\mathrm{NO}_{2}$ fluxes and lack of a $\mathrm{NO}_{2}$ diurnal cycle is compatible with, and further corroborates, the indication by positive glyoxal fluxes of chemistry within the SML rather than a gas-phase reaction below our inlet.
The $\mathrm{H}_{2} \mathrm{O}$ fluxes (Fig. 10c) are on the order of $0.5-$ $1.5 \times 10^{-3} \% \mathrm{VMR} \mathrm{m} \mathrm{s}^{-1}$ and consistently positive. A distinct diurnal variation is observed consistently between the $\mathrm{NH}$ and $\mathrm{SH}$, with minima just before sunrise and maxima several hours after solar noon. This increase in the $\mathrm{H}_{2} \mathrm{O}$ flux indicates faster evaporation of $\mathrm{H}_{2} \mathrm{O}$ from the ocean during the day. Notably, if imperfections in our current knowledge about absorption cross sections of water vapor were to severely overlap (and create cross-correlations) with glyoxal absorption structures, the water fluxes could become a driver for the glyoxal fluxes. However, no evidence for such a cross-correlation is observed. Indeed, while the direction of the water flux is consistently positive, glyoxal fluxes change direction over the course of the day. There is further an offset in the timing of minima/maxima. The independent behavior of diurnal variations in the $\mathrm{H}_{2} \mathrm{O}$ and glyoxal fluxes thus indicates that both gases are robust, and indicates that missing $\mathrm{H}_{2} \mathrm{O}$ absorption structures in spectral databases such as HIgh-resolution TRANsmission (HITRAN) are unlikely to affect the measured glyoxal fluxes.

$\mathrm{O}_{4}$ is not a stable molecule but the result of collisioninduced absorption of two $\mathrm{O}_{2}$ molecules (Thalman and Volkamer, 2013). If the $\mathrm{O}_{4}$ flux is converted to units of variations in the $\mathrm{O}_{2}$ mixing ratio, the corresponding $\mathrm{O}_{2}$ flux is always smaller than $10^{-3} \% \mathrm{O}_{2} \mathrm{VMR} \mathrm{m} \mathrm{s}^{-1}$, which corresponds to concentration changes in $\mathrm{O}_{2}$ that are 4-5 orders of magnitude smaller than the ambient $\mathrm{O}_{2} \mathrm{VMR}$ of $\sim 20.95 \%$ $\left(<10 \mathrm{ppm} \Delta \mathrm{O}_{2}\right)$. Fluxes of this magnitude are observed both positive and negative yet are about 2 orders of magnitude larger than the corresponding fluxes of $\mathrm{CO}_{2}$ (Blomquist et al., 2014). As such, we interpret the $\mathrm{O}_{4}$ fluxes to essentially reflect the noise in our measurements. These small upper limit fluxes reflect a very stable signal for $\mathrm{O}_{4}$; the change in this internal calibration gas is smaller: $0.4 \%$ of the typical $\mathrm{O}_{4}$ signal per hour (and not systematic).

Figure $\mathrm{S} 4$ shows a selection of ocean and atmospheric state parameters that are binned in the same fashion as the VMR and flux data and separated between $\mathrm{NH}$ and $\mathrm{SH}$ for archival.

\subsection{Context with satellite observations}

Global measurements of glyoxal from satellites agree that the eastern Pacific Ocean is a global hot spot for glyoxal over oceans (Wittrock et al., 2006; Lerot et al., 2010). In this context it is interesting to note that measurements by Sinreich et al. (2010) in a similar season and in a region that borders that probed here towards the east found average concentration of $63 \pm 21 \mathrm{pptv}$ that agree only marginally within error bounds with the in situ measurements presented in this study. This raises questions about a longitudinal variation in glyoxal at tropical latitudes, which had been observed by some satellites (Wittrock et al., 2006) but not by others (Lerot et al., 2010). Our in situ measurements in the NH probe a reasonably large longitude range and help assess this question. We do not find any obvious variation of glyoxal as a 
function of longitude. The average glyoxal VMR in the westerly NH cruise segment is $32 \pm 5$ pptv (average over 7 days; $13^{\circ} \mathrm{N}$ to 0 latitude; 133 to $105^{\circ} \mathrm{W}$ longitude), compared to $31 \pm 8$ pptv in the easterly $\mathrm{NH}$ cruise segment (average over 7 days; $13^{\circ} \mathrm{N}$ to 0 latitude; 105 to $80^{\circ} \mathrm{W}$ longitude). Early reports from SCIAMACHY found the annually averaged (year 2005) VCD of $4.5 \times 10^{14}$ and $6.0 \times 10^{14}$ molecules $\mathrm{cm}^{-2}$ VCD over the western and eastern cruise segments in the $\mathrm{NH}$ - and $3.5 \times 10^{14}$ molecules $\mathrm{cm}^{-2}$ over the SH cruise segment (Wittrock et al., 2006). Interestingly, measurements from the Global Ozone Monitoring Experiment-2 (GOME-2) satellite (Lerot et al., 2010) report $\sim 4.5 \times{ }^{14}$ molecules $\mathrm{cm}^{-2}$ in both regions of the $\mathrm{NH}$, i.e., find no evidence for a longitudinal variation in multiyear averaged data (2007 to 2009) and $\sim 3 \times 10^{14}$ molecules $\mathrm{cm}^{-2}$ over the SH cruise segment. The absence of a gradient over $3000 \mathrm{~km}$ distance in GOME-2 data is consistent with our data. However, it is interesting to note that the lower-limit VCDs of both satellite instruments correspond to $\sim 183$ pptv glyoxal in the $\mathrm{NH}$ and $\sim 120$ pptv glyoxal in the SH (assuming all glyoxal is located inside a $1 \mathrm{~km}$ high MBL). Such high glyoxal is not confirmed by our observations, or by the measurements of Sinreich et al. (2010). We note that the maximum concentration of 140 pptv reported by Sinreich et al. (2010) presents an extremely rare scenario that is not deemed representative of this data set (see their Fig. 3c). In situ and ship MAX-DOAS column observations (Sinreich et al., 2010; Mahajan et al., 2014) agree that there is insufficient glyoxal inside the MBL to explain satellite VCDs; this is particularly true over the $\mathrm{NH}$ tropical eastern Pacific Ocean (by a factor 2 to 6). Furthermore, our in situ data show glyoxal is more abundant in the $\mathrm{SH}$ tropical MBL. By contrast, both satellites find 25-42\% lowerglyoxal VCDs in the SH compared to the NH. The campaign average VMR during mornings in the SH ( $47 \pm 7$ pptv glyoxal) corresponds to $\sim 1.2 \times 10^{14}$ molecules $\mathrm{cm}^{-2}$ glyoxal VCD over the SH cruise segment, which is 2-3 times lower than long-time average VCD observed from space. The reason for this apparent mismatch in glyoxal amounts, and reversed hemispheric gradients, is currently not understood. A particularly interesting development to investigate the diurnal variation of glyoxal over oceans consists in the Tropospheric Emissions: Monitoring of Pollution (TEMPO) satellite mission (planned to launch in 2019), which will provide first time-resolved glyoxal VCD observations from geostationary orbit. Our diurnal profiles show further that glyoxal concentrations change by $30 \%$ over the course of the day. With the caveat that changes in MBL VMRs may not be indicative of VCD changes, this also implies that $\sim 15 \%$ lower VCDs are expected at the time of the Ozone Monitoring Instrument (OMI) satellite overpass (13:45 LT at the Equator). The differences between satellite and in situ measurements are as of yet difficult to reconcile. Notably, a direct comparison between in situ observations and column data is complicated due to the lack of vertical profile measurements of glyoxal at tropical latitudes, different averaging times, and spatial scales probed by in situ and column observations, as well as uncertain assumptions about a priori profiles, cloud screening, and other factors that influence air mass factor calculations. Some of these factors were further investigated from collocated measurements of glyoxal from aircraft during the TORERO project. The fast in situ LED-CE-DOAS instrument holds great potential for future deployments on research aircraft.

\section{Conclusions}

We have performed the first in situ measurements of glyoxal VMRs over oceans and presented first EC flux measurements of this soluble and short-lived molecule. Data from the first field deployment of the instrument are presented (26 days of measurements). The Fast LED-CE-DOAS instrument is a multispectral sensor suitable to measure eddy covariance fluxes of glyoxal and other gases selectively in the remote MBL. The measurement frequency of $\sim 2 \mathrm{~Hz}$ is sufficient to capture $\sim 90 \%$ of the glyoxal flux. Inlet and sampling line attenuation was determined using the measured response time of the instrument $\left(0.28 \pm 0.14 \mathrm{~s}\right.$, based on $\mathrm{O}_{4}$ measurements) and accounts for a correction of $<10 \%$. Multiple other gases are detected simultaneously with glyoxal and are exploited as follows: $\mathrm{NO}_{2}$ measurements are used to identify and filter data affected by stack contamination from the ship, and $\mathrm{NO}_{2}$ fluxes inform discussions about gas-phase chemistry below our inlet to be unlikely; $\mathrm{H}_{2} \mathrm{O}$ measurements are used to calculate ambient relative humidity, and $\mathrm{H}_{2} \mathrm{O}$ fluxes (consistently indicate evaporation) are used for correlative analysis of glyoxal fluxes and reveal a lack of any apparent correlation. Glyoxal is well separated from $\mathrm{H}_{2} \mathrm{O}$. The $\mathrm{H}_{2} \mathrm{O}$ fluxes help address concerns about spectral cross-correlation between missing water lines in the HITRAN database, and the lack of a $\mathrm{H}_{2} \mathrm{O}$ and glyoxal correlation further confirms the robustness of our retrievals. $\mathrm{O}_{4}$ measurements in ambient air are used an internal calibration gas to assure control over cavity alignment and mirror cleanliness (Thalman and Volkamer, 2010); further the pulsing of nitrogen gas into the inlet is monitored from fast high signal-to-noise measurements of $\mathrm{O}_{4}$ as part of individual spectra. $\mathrm{O}_{4}$ is then used to characterize sample transfer time through the sampling line, and to synchronize the clocks of the chemical sensor with that of the wind sensor. Two different methods showed excellent control over the phase correction from $\mathrm{O}_{4}$ measurements (average difference $\sim 0.11 \pm 0.10 \mathrm{~s}$ ) and give confidence in the EC flux measurements of glyoxal.

The campaign averaged VMR (all data) was $36 \pm 9$ pptv glyoxal. This is slightly less glyoxal compared to first measurements of glyoxal inside the MBL, which found $\sim 80 \mathrm{pptv}$ over the Sargasso Sea (Zhou and Mopper, 1990). It is possible that some continental outflow of terrestrial glyoxal might have contributed to these elevated glyoxal VMRs. Sinreich et al. (2010) reported $\sim 63 \pm 21$ pptv daytime glyoxal 
over the remote eastern tropical Pacific Ocean, which is in marginal agreement with the campaign average VMR of our in situ measurements. Recent reports of an average $\sim 25$ pptv glyoxal, and no more than 40 pptv, over a wide array of ocean environments (Mahajan et al., 2014) are slightly lower than our in situ observations. The comprehensive evidence generally supports the global presence of glyoxal over oceans as indicated by satellites (Wittrock et al., 2006; Lerot et al., 2010). Global glyoxal observations currently remain unexplained by atmospheric models (Myriofekalitakis et al., 2008; Fu et al., 2008; Stavrakou et al., 2009), and retrievals remain uncertain (Lerot et al., 2010; Alvarado et al., 2014; Miller et al., 2014) and largely untested.

The widespread positive flux that we observe in both hemispheres at night (more prevalent in the $\mathrm{SH}$ ) provides direct evidence that the SML is widespread (Wurl et al., 2011), and that oxidation reactions inside the SML are a source for OVOCs. A consistent increase is observed in the glyoxal VMR at night (both hemispheres) and suggests this SML source involves dark reactions of $\mathrm{O}_{3}$ that produce glyoxal. Notably, a recent laboratory study observed the volatilization of several OVOCs (including glyoxal) when $\mathrm{O}_{3}$ was flowed above a polyunsaturated fatty acid film on artificial saltwater in a flow reactor (Zhou et al., 2014). These results provide qualitative confirmation that the oxidation of the SML by $\mathrm{O}_{3}$ can be a source for OVOCs to the gas phase. However, the production rates found in this laboratory study are insufficient to explain any appreciable portion of the observed glyoxal over the tropical Pacific Ocean. The observed net fluxes are the balance between production and deposition fluxes. Observations of positive fluxes of glyoxal indicate that the SML production is significant and can dominate over considerable glyoxal deposition fluxes. Even the extremes among the positive EC net fluxes that we observe ( $\mathrm{SH}$ at night) can only explain a minor share of the sustained increase in glyoxal VMR overnight. The negative net flux during the day suggests that SML production chemistry is not the only source of glyoxal over oceans, and it points to the need for an atmospheric source to sustain the atmospheric glyoxal VMR during the day. Our observations locate chemistry at interfaces and emphasize the need to better understand heterogeneous chemistry. Heterogeneous chemistry as a source for volatile OVOCs could also be occurring on marine aerosols.

The Supplement related to this article is available online at doi:10.5194/amt-7-3579-2014-supplement.
Acknowledgements. The development of the Fast LED-CE-DOAS sensor was supported by the US National Science Foundation under NSF-CAREER award ATM-847793. The TORERO project is a US-SOLAS contribution, and it is supported by NSF under award AGS-1104104 (PI: R. Volkamer). S. Coburn is a recipient of a NASA Earth and Space Science Fellowship. The authors thank the captain and crew of the RV Ka'imimoana, Brian Lake and the NOAA TAO program, and David Welsh for their valuable support during the "TORERO cruise" KA-12-01. Mingxi Yang provided valuable comments on the manuscript.

Edited by: E. C. Apel

\section{References}

Alvarado, L. M. A., Richter, A., Vrekoussis, M., Wittrock, F., Hilboll, A., Schreier, S. F., and Burrows, J. P.: An improved glyoxal retrieval from OMI measurements, Atmos. Meas. Tech. Discuss., 7, 5559-5599, doi:10.5194/amtd-7-5559-2014, 2014.

Atkinson, R., Baulch, D. L., Cox, R. A., Hampson Jr., R. F., Kerr, J. A., Rossi, M. J., and Troe, J.: Evaluated Kinetic, Photochemical and Heterogeneous Data for Atmospheric Chemistry: Supplement V. IUPAC Subcommittee on Gas Kinetic Data Evaluation for Atmospheric Chemistry, J. Phys. Chem. Ref. Data, 26, 521-1011, doi:10.1063/1.556011, 1997.

Atkinson, R., Baulch, D. L., Cox, R. A., Crowley, J. N., Hampson, R. F., Hynes, R. G., Jenkin, M. E., Rossi, M. J., Troe, J., and IUPAC Subcommittee: Evaluated kinetic and photochemical data for atmospheric chemistry: Volume II - gas phase reactions of organic species, Atmos. Chem. Phys., 6, 3625-4055, doi:10.5194/acp-6-3625-2006, 2006.

Ayers, G. P., Gillet, R. W., Granek, H., deServes, C., and Cox., R. A.: Formaldehyde production in clean marine air, Geophys. Res. Lett., 24, 401-404, doi:10.1029/97GL00123, 1997.

Baldocchi, D., Falge, E., Gu, L., Olson, R., Hollinger, D., Running, S., Anthoni, P., Bernhofer, C., Davis, K., Evans, R., Fuentes, J., Goldstein, A., Katul, G., Law, B., Lee, X., Malhi, Y., Meyers, T., Munger, W., Oechel, W., U, K., Pilegaard, K., Schmid, H., Valentini, R., Verma, S., Vesala, T., Wilson, K., and Wofsy, S.: FLUXNET: A new tool to study the temporal and spatial variability of ecosystemscale carbon dioxide, water vapor, and energy flux densities, Bull. Am. Meteorol. Soc., 82, 2415-2434, doi:10.1175/15200477(2001)082<2415:FANTTS>2.3.CO;2, 2001.

Bariteau, L., Helmig, D., Fairall, C. W., Hare, J. E., Hueber, J., and Lang, E. K.: Determination of oceanic ozone deposition by shipborne eddy covariance flux measurements, Atmos. Meas. Tech., 3, 441-455, doi:10.5194/amt-3-441-2010, 2010.

Bell, T. G., De Bruyn, W., Miller, S. D., Ward, B., Christensen, K. H., and Saltzman, E. S.: Air-sea dimethylsulfide (DMS) gas transfer in the North Atlantic: evidence for limited interfacial gas exchange at high wind speed, Atmos. Chem. Phys., 13, 1107311087, doi:10.5194/acp-13-11073-2013, 2013.

Blomquist, B. W., Fairall, C. W., Huebert, B. J., Kieber, D. J., and Westby, G. R.: DMS sea-air transfer velocity: Direct measurements by eddy covariance and parameterization based on the NOAA/COARE gas transfer model, Geophys. Res. Lett., 33, L07601, doi:10.1029/2006GL025735, 2006. 
Blomquist, B. W., Huebert, B. J., Fairall, C. W., and Faloona, I. C.: Determining the sea-air flux of dimethylsulfide by eddy correlation using mass spectrometry, Atmos. Meas. Tech., 3, 1-20, doi:10.5194/amt-3-1-2010, 2010.

Blomquist, B. W., Fairall, C. W., Huebert, B. J., and Wilson, S. T.: Direct measurement of the oceanic carbon monoxide flux by eddy correlation, Atmos. Meas. Tech., 5, 3069-3075, doi:10.5194/amt-5-3069-2012, 2012.

Blomquist, B. W., Huebert, B. J., Fairall, C. W., Bariteau, L., Edson, J. B., Hare, J. E., and McGillis, W. R.: Advances in Air-Sea $\mathrm{CO}_{2}$ Flux Measurement by Eddy Correlation, Bound.-Lay. Meteorol., 152, 3, 245-276, doi:10.1007/s10546-014-9926-2, 2014.

Coburn, S., Dix, B., Sinreich, R., and Volkamer, R.: The CU ground MAX-DOAS instrument: characterization of RMS noise limitations and first measurements near Pensacola, FL of BrO, IO, and CHOCHO, Atmos. Meas. Tech., 4, 2421-2439, doi:10.5194/amt-4-2421-2011, 2011.

Edson, J. B., Hinton, A. A., Prada, K. E., Hare, J. E., and Fairall, C. W.: Direct covariance flux estimates from mobile platforms at sea, J. Atmos. Ocean. Technol., 15, 547-562, doi:10.1175/15200426(1998)015<0547:DCFEFM>2.0.CO;2, 1998.

Edson, J. B., Fairall, C. W., Bariteau, L., Zappa, C. J., CifuentesLorenzen, A., McGillis, W. R., Pezoa, S., Hare, J. E., and Helmig, D.: Direct covariance measurement of $\mathrm{CO}_{2}$ gas transfer velocity during the 2008 Southern Ocean Gas Exchange Experiment: Wind speed dependency, J. Geophys. Res.-Ocean., 116, C00F10, doi:10.1029/2011JC007022, 2011.

Ervens, B. and Volkamer, R.: Glyoxal processing by aerosol multiphase chemistry: towards a kinetic modeling framework of secondary organic aerosol formation in aqueous particles, Atmos. Chem. Phys., 10, 8219-8244, doi:10.5194/acp-10-8219-2010, 2010.

Fairall, C. W., White, A. B., Edson, J. B., and Hare, J. E.: Integrated shipboard measurements of the marine boundary layer, J. Atmos. Ocean. Technol., 14, 338-359, doi:10.1175/15200426(1997)014<0338:ISMOTM>2.0.CO;2, 1997.

Fairall, C. W., Hare, J. E., Edson, J. B., and McGillis, W. R.: Parameterization and Micrometeorological Measurement of Air-Sea Gas Transfer, Bound.-Lay. Metorol., 96, 63-106, doi:10.1023/A:1002662826020, 2000.

Finlayson-Pitts, B. and Pitts, J. N.: Chemistry of the upper and lower atmosphere: theory, experiments, and applications, Academic Press, United States of America, 2000.

Fu, T., Jacob, D. J., Wittrock, F., Burrows, J. P., Vrekoussis, M., and Henze, D. K.: Global budgets of atmospheric glyoxal and methylglyoxal, and implications for formation of secondary organic aerosols, J. Geophys. Res.-Atmos., 113, D15303, doi:10.1029/2007JD009505, 2008.

Grosjean, D., Grosjean, E., and Gertler, A. W.: On-road emissions of carbonyls from light-duty and heavy-duty vehicles, Environ. Sci. Technol., 35, 45-53, doi:10.1021/es001326a, 2001.

Hays, M. D., Geron, C. D., Linna, K. J., and Smith, N. D.: Speciation of Gas-Phase and Fine Particle Emissions from Burning of Foliar Fuels, Environ. Sci. Technol., 36, 2281-2295, doi:10.1021/es0111683, 2002.

Helmig, D., Lang, E. K., Bariteau, L., Boylan, P., Fairall, C. W., Ganzeveld, L., Hare, J. E., Hueber, J., and Pallandt, M.: Atmosphere-ocean ozone fluxes during the TexAQS 2006, STRATUS 2006, GOMECC 2007, GasEx 2008, and
AMMA 2008 cruises, J. Geophys. Res.-Atmos., 117, D04305, doi:10.1029/2011JD015955, 2012.

Huebert, B., Blomquist, B., Hare, J., Fairall, C., Johnson, J., and Bates, T.: Measurement of the sea-air DMS flux and transfer velocity using eddy correlation, Geophys. Res. Lett., 31, L23113, doi:10.1029/2004GL021567, 2004.

Kaimal, J., Izumi, Y., Wyngaard, J., and Cote, R.: Spectral Characteristics of Surface-Layer Turbulence, Q. J. R. Meteorol. Soc., 98, 563-589, doi:10.1002/qj.49709841707, 1972.

Kean, A. J., Grosjean, E., and Grosjean, D.: On-road measurement of carbonyls in California light-duty vehicle emissions, Environ. Sci. Technol., 35, 4198-4204, doi:10.1021/es010814v, 2001.

Kieber, R., Zhou, X., and Mopper, K.: Formation of CarbonylCompounds from Uv-Induced Photodegradation of Humic Substances in Natural-Waters - Fate of Riverine Carbon in the Sea, Limnol. Oceanogr., 35, 1503-1515, 1990.

Kondo, F. and Tsukamoto, O.: Air-sea $\mathrm{CO}_{2}$ flux by eddy covariance technique in the equatorial Indian Ocean, J. Oceanogr., 63, 449456, doi:10.1007/s10872-007-0040-7, 2007.

Lenschow, D. and Raupach, M.: The Attenuation of Fluctuations in Scalar Concentrations through Sampling Tubes, J. Geophys. Res.-Atmos., 96, 15259-15268, doi:10.1029/91JD01437, 1991.

Lerot, C., Stavrakou, T., De Smedt, I., Müller, J.-F., and Van Roozendael, M.: Glyoxal vertical columns from GOME-2 backscattered light measurements and comparisons with a global model, Atmos. Chem. Phys., 10, 12059-12072, doi:10.5194/acp10-12059-2010, 2010.

Liggio, J., Li, S., and McLaren, R.: Reactive uptake of glyoxal by particulate matter, J. Geophys. Res.-Atmos., 110, D10304, doi:10.1029/2004JD005113, 2005.

Logan, J. A.: Nitrogen-oxides in the troposphere - Global and regional budgets, J. Geophys. Res.-Ocean. Atmos., 88, NC15, 785807, doi:10.1029/JC088iC15p10785, 1983.

Mahajan, A. S., Prados-Roman, C., Hay, T. D., Lampel, J., Pöhler, D., Großmann, K., Tschritter, J., Frieß, U., Platt, U., Johnston, P., Kreher, K., Wittrock, F., Burrows, J. P., Plane, J. M. C., and Saiz-Lopez, A.: Glyoxal observations in the global marine boundary layer, J. Geophys. Res.-Atmos., 2013, JD021388, doi:10.1002/2013JD021388, 2014.

Marandino, C. A., De Bruyn, W. J., Miller, S. D., Prather, M. J., and Saltzman, E. S.: Oceanic uptake and the global atmospheric acetone budget, Geophys. Res. Lett., 32, L15806, doi:10.1029/2005GL023285, 2005.

Marandino, C. A., De Bruyn, W. J., Miller, S. D., and Saltzman, E. S.: Eddy correlation measurements of the air/sea flux of dimethylsulfide over the North Pacific Ocean, J. Geophys. Res.Atmos., 112, D03301, doi:10.1029/2006JD007293, 2007.

Marandino, C. A., De Bruyn, W. J., Miller, S. D., and Saltzman, E. S.: DMS air/sea flux and gas transfer coefficients from the North Atlantic summertime coccolithophore bloom, Geophys. Res. Lett., 35, L23812, doi:10.1029/2008GL036370, 2008.

Marandino, C. A., De Bruyn, W. J., Miller, S. D., and Saltzman, E. S.: Open ocean DMS air/sea fluxes over the eastern South Pacific Ocean, Atmos. Chem. Phys., 9, 345-356, doi:10.5194/acp9-345-2009, 2009.

McGillis, W., Edson, J., Hare, J., and Fairall, C.: Direct covariance air-sea $\mathrm{CO}_{2}$ fluxes, J. Geophys. Res.-Ocean., 106, 16729-16745, doi:10.1029/2000JC000506, 2001. 
McGillis, W., Edson, J., Zappa, C., Ware, J., McKenna, S., Terray, E., Hare, J., Fairall, C., Drennan, W., Donelan, M., DeGrandpre, M., Wanninkhof, R., and Feely, R.: Air-sea $\mathrm{CO}_{2}$ exchange in the equatorial Pacific, J. Geophys. Res.-Ocean., 109, C08S02, doi:10.1029/2003JC002256, 2004.

Miller, C. C., Abad, G. G., Wang, H., Liu, X., Kurosu, T., Jacob, D. J., and Chance, K.: Glyoxal retrieval from the Ozone Monitoring Instrument, Atmos. Meas. Tech. Discuss., 7, 6065-6112, doi:10.5194/amtd-7-6065-2014, 2014.

Miller, S., Marandino, C., de Bruyn, W., and Saltzman, E. S.: Air-sea gas exchange of $\mathrm{CO}_{2}$ and DMS in the North Atlantic by eddy covariance, Geophys. Res. Lett., 36, L15816, doi:10.1029/2009GL038907, 2009.

Miller, S. D., Marandino, C., and Saltzman, E. S.: Ship-based measurement of air-sea $\mathrm{CO}_{2}$ exchange by eddy covariance, J. Geophys. Res.-Atmos., 115, D02304, doi:10.1029/2009JD012193, 2010.

Millet, D. B., Guenther, A., Siegel, D. A., Nelson, N. B., Singh, H. B., de Gouw, J. A., Warneke, C., Williams, J., Eerdekens, G., Sinha, V., Karl, T., Flocke, F., Apel, E., Riemer, D. D., Palmer, P. I., and Barkley, M.: Global atmospheric budget of acetaldehyde: 3-D model analysis and constraints from in-situ and satellite observations, Atmos. Chem. Phys., 10, 3405-3425, doi:10.5194/acp-10-3405-2010, 2010.

Myriokefalitakis, S., Vrekoussis, M., Tsigaridis, K., Wittrock, F., Richter, A., Brühl, C., Volkamer, R., Burrows, J. P., and Kanakidou, M.: The influence of natural and anthropogenic secondary sources on the glyoxal global distribution, Atmos. Chem. Phys., 8, 4965-4981, doi:10.5194/acp-8-4965-2008, 2008.

Norman, M., Rutgersson, A., Sorensen, L. L., and Sahlee, E.: Methods for Estimating Air-Sea Fluxes of $\mathrm{CO}_{2}$ Using HighFrequency Measurements, Bound.-Lay. Meteorol., 144, 379400, doi:10.1007/s10546-012-9730-9, 2012.

Olasehinde, E. F., Takeda, K., and Sakugawa, H.: Photochemical production and consumption mechanisms of nitric oxide in seawater, Environ. Sci. Technol., 44, 8403-8408, doi:10.1021/es101426x, 2010.

Platt, U.: Differential optical absorption spectroscopy (DOAS), in: Air Monitoring by Spectroscopic Techniques, edited by: Sigrist, M. W., John Wiley \& Sons, Inc., New York, 127, 1994.

Platt, U., Perner, D., and Patz, H.: Simultaneous Measurement of Atmospheric Ch2o, O3, and No2 by Differential OpticalAbsorption, J. Geophys. Res.-Ocean. Atmos., 84, 6329-6335, doi:10.1029/JC084iC10p06329, 1979.

Ruiz-Montoya, M. and Rodriguez-Mellado, J. M.: Use of convolutive potential sweep voltammetry in the calculation of hydration equilibrium constants of $\alpha$-dicarbonyl compounds, J. Electroanal. Chem., 370, 183-187, 1994.

Ruiz-Montoya, M. and Rodriguez-Mellado, J. M.: Hydration constants of carbonyl and dicarbonyl compounds comparison between electrochemcial and no electrochemcial techniques, Portugaliae Electrochim. Acta, 13, 299-303, 1995.

Ryerson, T. B., Andrews, A. E., Angevine, W. M., Bates, T. S., Brock, C. A., Cairns, B., Cohen, R. C., Cooper, O. R., de Gouw, J. A., Fehsenfeld, F. C., Ferrare, R. A., Fischer, M. L., Flagan, R. C., Goldstein, A. H., Hair, J. W., Hardesty, R. M., Hostetler, C. A., Jimenez, J. L., Langford, A. O., McCauley, E., McKeen, S. A., Molina, L. T., Nenes, A., Oltmans, S. J., Parrish, D. D., Pederson, J. R., Pierce, R. B., Prather, K., Quinn, P. K., Seinfeld, J. H.,
Senff, C. J., Sorooshian, A., Stutz, J., Surratt, J. D., Trainer, M., Volkamer, R., Williams, E. J., and Wofsy, S. C.: The 2010 California Research at the Nexus of Air Quality and Climate Change (CalNex) field study, J. Geophys. Res.-Atmos., 118, 5830-5866, doi:10.1002/jgrd.50331, 2013.

Sinreich, R., Coburn, S., Dix, B., and Volkamer, R.: Ship-based detection of glyoxal over the remote tropical Pacific Ocean, Atmos. Chem. Phys., 10, 11359-11371, doi:10.5194/acp-1011359-2010, 2010.

Stavrakou, T., Müller, J.-F., De Smedt, I., Van Roozendael, M., Kanakidou, M., Vrekoussis, M., Wittrock, F., Richter, A., and Burrows, J. P.: The continental source of glyoxal estimated by the synergistic use of spaceborne measurements and inverse modelling, Atmos. Chem. Phys., 9, 8431-8446, doi:10.5194/acp-98431-2009, 2009.

Taddei, S., Toscano, P., Gioli, B., Matese, A., Miglietta, F., Vaccari, F. P., Zaldei, A., Custer, T., and Williams, J.: Carbon Dioxide and Acetone Air-Sea Fluxes over the Southern Atlantic, Environ. Sci. Technol., 43, 5218-5222, doi:10.1021/es8032617, 2009.

Thalman, R. and Volkamer, R.: Inherent calibration of a blue LED-CE-DOAS instrument to measure iodine oxide, glyoxal, methyl glyoxal, nitrogen dioxide, water vapour and aerosol extinction in open cavity mode, Atmos. Meas. Tech., 3, 1797-1814, doi:10.5194/amt-3-1797-2010, 2010.

Thalman, R. and Volkamer, R.: Temperature dependent absorption cross-sections of O2-O2 collision pairs between 340 and $630 \mathrm{~nm}$ and at atmospherically relevant pressure, Phys. Chem. Chem. Phys., 15, 15371-15381, doi:10.1039/c3cp50968k, 2013.

Thalman, R., Baeza-Romero, M. T., Ball, S. M., Borrás, E., Daniels, M. J. S., Goodall, I. C. A., Henry, S. B., Karl, T., Keutsch, F. N., Kim, S., Mak, J., Monks, P. S., Muñoz, A., Orlando, J., Peppe, S., Rickard, A. R., Ródenas, M., Sánchez, P., Seco, R., Su, L., Tyndall, G., Vázquez, M., Vera, T., Waxman, E., and Volkamer, R.: Instrument inter-comparison of glyoxal, methyl glyoxal and $\mathrm{NO}_{2}$ under simulated atmospheric conditions, Atmos. Meas. Tech. Discuss., 7, 8581-8642, doi:10.5194/amtd-7-8581-2014, 2014.

Vandaele, A. C., Hermans, C., Simon, P. C., Carleer, M., Colin, R., Fally, S., Mérienne, M. F., Jenouvrier, A. and Coquart, B.: Measurements of the $\mathrm{NO}_{2}$ absorption cross-section from 42, $000 \mathrm{~cm}^{-1}$ to $10000 \mathrm{~cm}^{-1}(238-1000 \mathrm{~nm})$ at $220 \mathrm{~K}$ and 294 K, J. Quant. Spectrosc. Ra., 59, 171-184, doi:10.1016/S00224073(97)00168-4, 1998.

van Pinxteren, M. and Herrmann, H.: Glyoxal and methylglyoxal in Atlantic seawater and marine aerosol particles: method development and first application during the Polarstern cruise ANT XXVII/4, Atmos. Chem. Phys., 13, 11791-11802, doi:10.5194/acp-13-11791-2013, 2013.

Volkamer, R., Spietz, P., Burrows, J., and Platt, U.: High-resolution absorption cross-section of glyoxal in the UV-vis and IR spectral ranges, J. Photochem. Photobiol. A-Chem., 172, 35-46, doi:10.1016/j.jphotochem.2004.11.011, 2005.

Volkamer, R., San Martini, F., Molina, L. T., Salcedo, D., Jimenez, J. L., and Molina, M. J.: A missing sink for gas-phase glyoxal in Mexico City: Formation of secondary organic aerosol, Geophys. Res. Lett., 34, L19807, doi:10.1029/2007GL030752, 2007.

Volkamer, R., Ziemann, P. J., and Molina, M. J.: Secondary Organic Aerosol Formation from Acetylene $\left(\mathrm{C}_{2} \mathrm{H}_{2}\right)$ : seed effect on SOA yields due to organic photochemistry in the aerosol aque- 
ous phase, Atmos. Chem. Phys., 9, 1907-1928, doi:10.5194/acp9-1907-2009, 2009.

Vrekoussis, M., Wittrock, F., Richter, A., and Burrows, J. P.: Temporal and spatial variability of glyoxal as observed from space, Atmos. Chem. Phys., 9, 4485-4504, doi:10.5194/acp-9-44852009, 2009.

Waxman, E. M., Dzepina, K., Ervens, B., Lee-Taylor, J., Aumont, B., Jimenez, J. L., Madronich, S., and Volkamer, R.: Secondary organic aerosol formation from semi- and intermediate-volatility organic compounds and glyoxal: Relevance of $\mathrm{O} / \mathrm{C}$ as a tracer for aqueous multiphase chemistry, Geophys. Res. Lett., 40, 978982, doi:10.1002/grl.50203, 2013.

Wittrock, F., Richter, A., Oetjen, H., Burrows, J. P., Kanakidou, M., Myriokefalitakis, S., Volkamer, R., Beirle, S., Platt, U., and Wagner, T.: Simultaneous global observations of glyoxal and formaldehyde from space, Geophys. Res. Lett., 33, L16804, doi:10.1029/2006GL026310, 2006.

Wurl, O., Wurl, E., Miller, L., Johnson, K., and Vagle, S.: Formation and global distribution of sea-surface microlayers, Biogeosciences, 8, 121-135, doi:10.5194/bg-8-121-2011, 2011.

Yang, M., Nightingale, P. D., Beale, R., Liss, P. S., Blomquist, B., and Fairall, C.: Atmospheric deposition of methanol over the Atlantic Ocean, Proc. Natl. Acad. Sci. USA, 110, 20034-20039, doi:10.1073/pnas.1317840110, 2013.

Yang, M., Beale, R., Liss, P., Johnson, M., Blomquist, B., and Nightingale, P.: Air-sea fluxes of oxygenated volatile organic compounds across the Atlantic Ocean, Atmos. Chem. Phys., 14, 7499-7517, doi:10.5194/acp-14-7499-2014, 2014.
Zafiriou, O. C., McFarland, M., and Bromund, R. H.: Nitric-Oxide in seawater, Science, 207, 637-639, doi:10.1126/science.207.4431.637, 1980.

Zafiriou, O. C. and McFarland, M.: Nitric-Oxide from nitrate photolysis in the Central Equatorial Pacific, J. Geophys. Res.- Oc. Atm., 86, 3173-3182, doi:10.1029/JC086iC04p03173, 1981.

Zhou, S., Gonzalez, L., Leithead, A., Finewax, Z., Thalman, R., Vlasenko, A., Vagle, S., Miller, L.A., Li, S.-M., Bureekul, S., Furutani, H., Uematsu, M., Volkamer, R., and Abbatt, J.: Formation of gas-phase carbonyls from heterogeneous oxidation of polyunsaturated fatty acids at the air-water interface and of the sea surface microlayer, Atmos. Chem. Phys., 14, 1371-1384, doi:10.5194/acp-14-1371-2014, 2014.

Zhou, X. L. and Mopper, K.: Apparent Partition-Coefficients of 15 Carbonyl-Compounds between Air and Seawater and between Air and Fresh-Water - Implications for Air Sea Exchange, Environ. Sci. Technol., 24, 1864-1869, doi:10.1021/es00082a013, 1990.

Zhou, X. L. and Mopper, K.: Photochemical production of lowmolecular-weight carbonyl compounds in seawater and surface microlayer and their air-sea exchange, Mar. Chem., 56, 201-213, doi:10.1016/S0304-4203(96)00076-X, 1997. 